OPEN ACCESS

Edited by:

Senentxu Lanceros-Mendez,

Basque Center for Materials,

Applications and Nanostructures,

Spain

Reviewed by:

Matthew Shawkey,

Ghent University, Belgium

Margarida Quina,

University of Coimbra, Portugal

*Correspondence:

Maxwell Hincke

mhincke@uottawa.ca

Specialty section:

This article was submitted to

Biomaterials,

a section of the journal

Frontiers in Bioengineering and

Biotechnology

Received: 03 March 2021

Accepted: 01 June 2021

Published: 06 July 2021

Citation:

Ahmed TAE, Wu L, Younes $M$ and Hincke M (2021) Biotechnological Applications of Eggshell: Recent

Advances.

Front. Bioeng. Biotechnol. 9:675364. doi: 10.3389/fbioe.2021.675364

\section{Biotechnological Applications of Eggshell: Recent Advances}

\author{
Tamer A. E. Ahmed ${ }^{1,2}$, Ling Wu ${ }^{1}$, Manar Younes ${ }^{1}$ and Maxwell Hincke ${ }^{1,3 *}$ \\ ${ }^{1}$ Department of Cellular and Molecular Medicine, Faculty of Medicine, University of Ottawa, Ottawa, ON, Canada, ${ }^{2}$ School \\ of Nutrition Sciences, Faculty of Health Sciences, University of Ottawa, Ottawa, ON, Canada, ${ }^{3}$ Department of Innovation \\ in Medical Education, Faculty of Medicine, University of Ottawa, Ottawa, ON, Canada
}

The eggshell (ES) provides protection against pathogenic and physical insults while supplying essential metabolic and nutritional needs for the growing avian embryo. It is constituted mainly of calcium carbonate arranged as calcite crystals. The global chicken egg production in 2018 was over 76.7 million metric tons. In industrialized countries, about $30 \%$ of eggs are processed at breaker plants that produce liquid egg products and large quantities of solid ES waste. ES waste is utilized for a variety of low-value applications, or alternatively is disposed in landfill with associated economic and environmental burdens. The number of patents pertaining to ES applications has increased dramatically in recent years; of 673 patents granted in the last century, $536(80 \%)$ were published in the last two decades. This review provides a snapshot of the most recent patents published between 2015 and 2020, with emphasis on different biotechnological applications of ES waste, and summarizes applications for biomedical, chemical, engineering, and environmental technologies. Biomedical technologies include the production of calcium lactate, calcium phosphate, and healthpromoting products, while chemical technologies include plant growth promoters, food processing and production, and biodiesel oil catalysis along with active calcium, carbon, soluble proteins, organic calcium, and ultrafine calcium carbonate sources. Engineering technologies address material engineering and nanoparticle production, while environmental technologies pertain to production of biomass, solubilization of sludge as well as production of magnetic ES adsorbents and adsorption of heavy metals, organics, total nitrogen and fluoride, soil pollutants, and radioactive compounds. Although the number of ES-based patents has exponentially increased in the last decade, exploration of innovative top-down approaches and ES development as a physical platform are new endeavors that are expected to further increase the upscaling of ES waste exploitation.

\footnotetext{
Keywords: eggshell, patents, biotechnological applications, biomedical, chemical, engineering, environmental, technologies
}

\section{INTRODUCTION}

\section{Eggshell Function and Composition}

The calcareous egg is a reproductive vehicle for all avian and most reptilian species. The avian egg represents the most complex amniotic egg in oviparous vertebrates (Hincke et al., 2012). The eggshell (ES) has evolved to offer protection against physical and pathogenic insults while providing metabolic and nutritional needs for the growing embryo (Rose and Hincke, 2009; 
Hincke et al., 2012; Stapane et al., 2019). The partial dissolution and associated thinning of ES during fertilized egg incubation provides calcium for calcium-phosphate mineralization of the growing embryonic chick skeletal system, along with facilitating the chick hatching/pipping at the end of incubation (Athanasiadou et al., 2018).

The chicken ES is constituted of calcium-carbonate $\left(\mathrm{CaCO}_{3}\right)$ mineral in the form of calcite $(\sim 95 \%)$ and organic material/matrix ( 3.5\%; Athanasiadou et al., 2018). The organic matrix consists of proteins and proteoglycans that interact with the forming mineral phase to confer specific microstructural and mechanical properties to ES (Hincke et al., 2012). ES-specific matrix proteins direct the protective functions of ES during avian reproduction, through regulation of ES mineralization (physical protection) and antimicrobial defense (chemical protection; Rose and Hincke, 2009). The ES presents a multi-laminated resilient structure consisting (from inner to outer) of eggshell membranes (ESM), mammillary cone layer, palisade layer, and cuticle (Nys et al., 2004; Hincke et al., 2012; Figure 1).

\section{Egg Market}

Chicken eggs are a vital part of the daily human diet worldwide and serve as a cost-effective and high-quality nutritious food (Ahmed et al., 2019a). Global egg production in 2018 was over 76.7 million metric tons (Shahbandeh, 2020). The five leading egg-producing countries are China, United States, Indonesia, India, and Mexico which together contributed approximately $63 \%$ of total global egg production ( 1,652 billion eggs, 99 million tonnes) in 2019 (FAO, 2020).

In industrialized countries, about $30 \%$ of shell eggs are redirected to breaker processing plants to produce liquid egg products, and are not consumed as shell eggs (Cordeiro and Hincke, 2011; Ahmed et al., 2019a,b). ES and the associated ESM represent approximately $10 \%$ of egg weight and are therefore produced in large quantities as a byproduct of the egg-processing industries, estimated at 2.3 million tons worldwide (Hincke et al., 2012; Laca et al., 2017). The solid ES residues generated by these operations are often discarded in landfill sites without any pre-treatment (Cordeiro and Hincke, 2011). Decomposition of ES, ESM and the associated residual egg white (EW) leads to the release of ammonia $\left(\mathrm{NH}_{3}\right)$ and hydrogen sulfide $\left(\mathrm{H}_{2} \mathrm{~S}\right)$ with an offensive odor, which attracts rodents and insects (Owuamanam and Cree, 2020). Industrial egg producers must dispose ES waste properly in landfill sites according to local environmental regulations; however, this discards the potentially valuable calcium carbonate and bioactive protein constituents. Furthermore, the costs associated with landfill disposal of egg waste are projected to climb with inflation (Ahmed et al., 2019a).

\section{Eggshell Waste and Disposal}

Globally, the total amount of ES waste was about 2.3 million tonnes in 2018 (Hincke et al., 2012; Laca et al., 2017; Ahmed et al., 2019a). China produced 458,448 million eggs in 2018 (FAO, 2020), of which 137,534 million eggs were processed in breaking plants and generating 825,204 tonnes of mineral-rich ES waste. In the United States, ES waste generated by food industries is ranked 15th on the Environmental Protection Agency list of waste that creates pollution problems, as its disposition in landfill leads to environmental issues. The cost of ES waste disposal to landfill by one American breaker plant can be approximately $\$ 100,000$ USD annually (Owuamanam and Cree, 2020). In Canada, all egg producers together pay about \$0.8-1.6 million USD to dispose of ES waste (Canadian Food Innovators, 2015). In Europe, small or medium-sized egg enterprises spend \$127,000 USD per year for ES waste disposal (Shellbrane, 2012). More specifically, Just Egg Ltd. (Chilled foods, United Kingdom), which produces 17.7 tons of ES waste annually, claims that it spends $\$ 66,000$ USD per year to dispose of this material (Shearman, 2016; Just Egg Ltd., 2020).

\section{Eggshell Waste Added-Value Applications}

Eggshell waste is rich in bioactive compounds; therefore, there is increasing investment in research to develop value-added ES-derived products with commercial applications (Cordeiro and Hincke, 2011). A large number of applications to generate value-added products from ES waste have been patented; their number has exponentially increased during the last two decades (Figures 2-4).

In 2012, the European Commission and the Seventh Framework Program (FP7) funded a 2-year project entitled "Separating ES and its membrane to turn ES waste into valuable source materials," with a budget of over 1.5 million $€$ (Shellbrane, 2012), to help mitigate the environmental problem of ES waste (Shellbrane, 2012, 2019). The Consortium developed a prototype capable of processing $60 \mathrm{~kg} / \mathrm{h}$ of ES waste (about 10,000 eggs/hr), producing high quality ESM and ES. The prototype consists of three modules: separation, disinfection, and drying (CORDIS). A similar goal was implemented in Canada including funded projects for the repurposing of ES waste protein as potential medical and health-care spinoffs (Cordeiro and Hincke, 2011; Poultry Innovations Conference, 2013) and development of ES powder as a functional food ingredient (Canadian Food Innovators, 2015). The valorization of ES biowaste will improve both the environment and the balance sheets of egg producers.

\section{Potential Markets for Eggshell Waste}

The chicken ES consists of calcium carbonate $\left(\mathrm{CaCO}_{3}\right)$ mineral in the form of calcite $(\sim 95 \%)$ and organic material/matrix proteins ( $\sim 3.5 \%$; Hincke et al., 2012). The global market for calcium carbonate (ground and precipitated) is projected to reach USD 28.98 billion by the end of 2025, growing at a compound annual rate of 5.78\% (ReportLinker, 2020), without taking it into account as a substantial market for high calcium content ES waste. ES waste could be valorized as a partial replacement for commercial products such as limestone, pure calcium carbonate, soil conditioners, biomaterials, food additives or supplements, cosmetic or pharmaceuticals base, catalyst, and wastewater purifiers (Waheed et al., 2019; Mignardi et al., 2020; Owuamanam and Cree, 2020).

In 2019, more than 50\% of geologic calcium carbonate (limestone) was used for steel manufacturing, and the remaining market was shared by building and construction, water treatment, agriculture, paper and pulp, plastics, and paint 


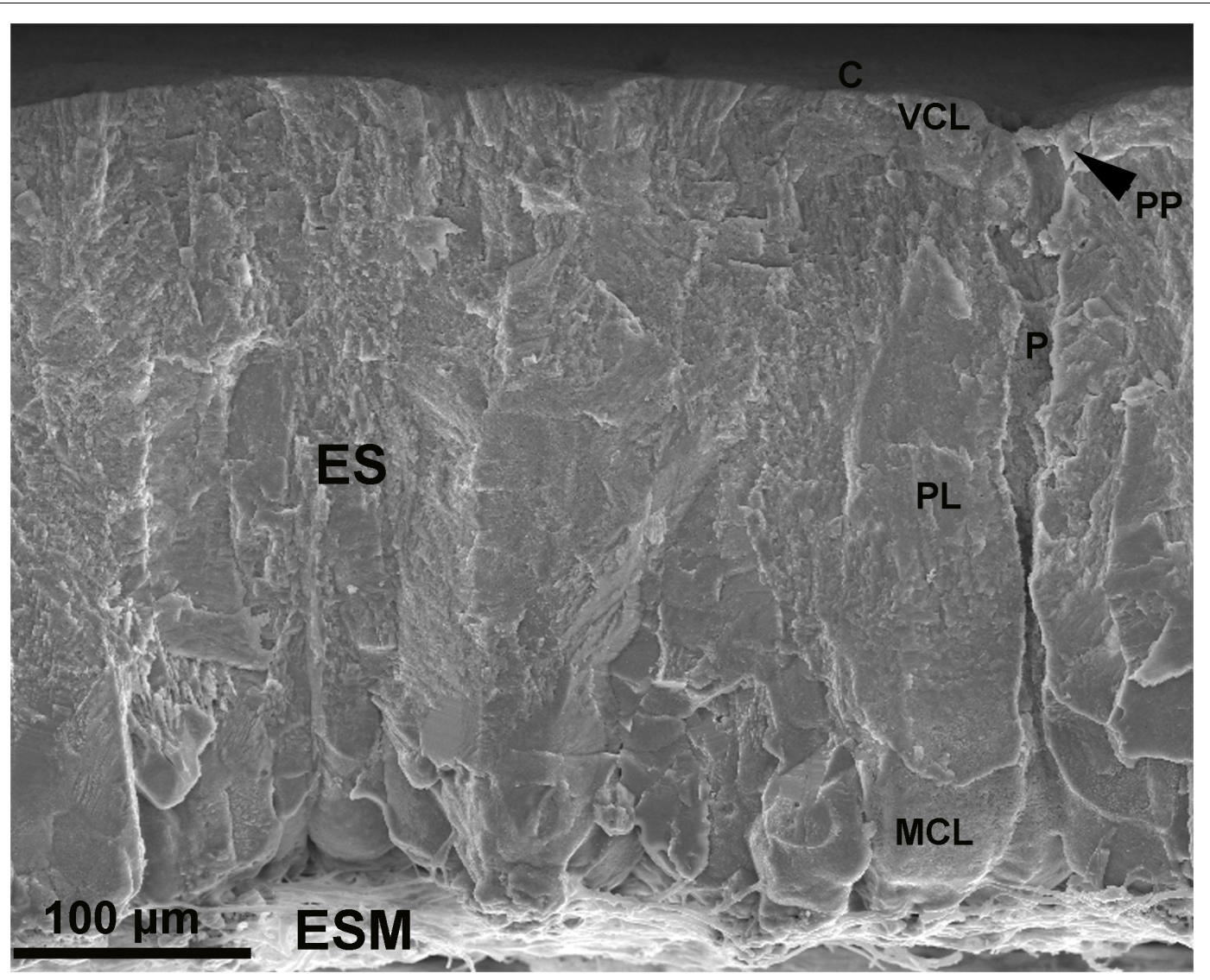

FIGURE 1 | Morphology of the eggshell and eggshell membranes revealed by scanning electron microscopy (SEM). Cross-fractured eggshell reveals the calcified eggshell (ES), constituted of cuticle (C), vertical crystal layer (VCL), palisade layer (PL), and mammillary cone layer (MCL); with the associated eggshell membranes (ESM). Respiratory pore (P); pore plug (PP). (Nano Imaging Facility, Carleton University, Ottawa, Canada).

(Cree and Rutter, 2015; Limestone, 2019; Lewicka et al., 2020). The price of commercially available calcium carbonate limestone powder is around \$200-350 USD/metric ton (Katsuyama et al., 2005). On average, about $88 \sim 270 \mathrm{~kg}$ limestone is used for the production of every ton of crude steel. According to the World Steel Association, 1870 million metric tons of steel were manufactured in 2019 (Mordor Intelligence, 2020), which requires limestone with a value of at least $\$ 33$ Bn USD. ES waste could partially replace limestone use in the steel industry, thus opening a substantial market. In addition, the building and construction industry is the second largest market for limestone consumption, in which Ordinary Portland Cement (OPC) is a precursor for concrete. The world production of OPC is predicted to exceed 5 billion metric tons by 2030 (Imbabi et al., 2012), which consumes limestone reserves. This depletion could be mitigated via the use of ES waste.

Another potential market for ES waste is paper manufacturing. The paper industry uses limestone-based raw material to produce fillers and coating pigments, such as $\mathrm{CaCO}_{3}$ pigment for printing paper and board (Gaber, 2018). In Europe, around 90 million tons of paper and board were produced in 2019, of which more than half were directed toward packaging (container board, carton board, and wrapping, etc.), in addition to graphic papers (newsprint, printing, and writing, etc.) and other uses (e.g., tissue; Limestone, 2019). In the largest European paper plants, around $385 \mathrm{~kg}$ of fillers $\left(\mathrm{CaCO}_{3}\right)$ and coating pigments $\left(\mathrm{CaCO}_{3}\right.$ and kaolin) are used for every ton of paper production. These paper plants produced over 1,200 million tons of paper in 2012 that required approximately 47,300 tons of $\mathrm{CaCO}_{3}$ and kaolin, which is another market for ES waste (Lewicka et al., 2020). In addition, ES showed potential as a replacement for limestone to prepare hydroxyapatite (HAP) utilized for the sustainable treatment of toxic metal-polluted water. The transformation of ES into ES-based hydroxyapatite (ESHAP) on an industrial scale was claimed to create an investment return at least 5 times greater than the cost of conventional disposal expenses (Mignardi et al., 2020).

Calcium compounds are part of the broad applications market for calcium carbonate, calcium citrate, calcium phosphate, and calcium chloride, etc. in the biomedical, nutritional and pharmaceutical sectors. The global calcium citrate and calcium phosphate markets are anticipated to reach USD 900 million by 2025 (Ahuja and Rawat, 2019). Commercial calcium supplements are commonly produced from dried shrimp, fish, oyster shells, coral, and algae (Xu et al., 2020), the use of which might not be ecologically sustainable going forward. ES is an acceptable 


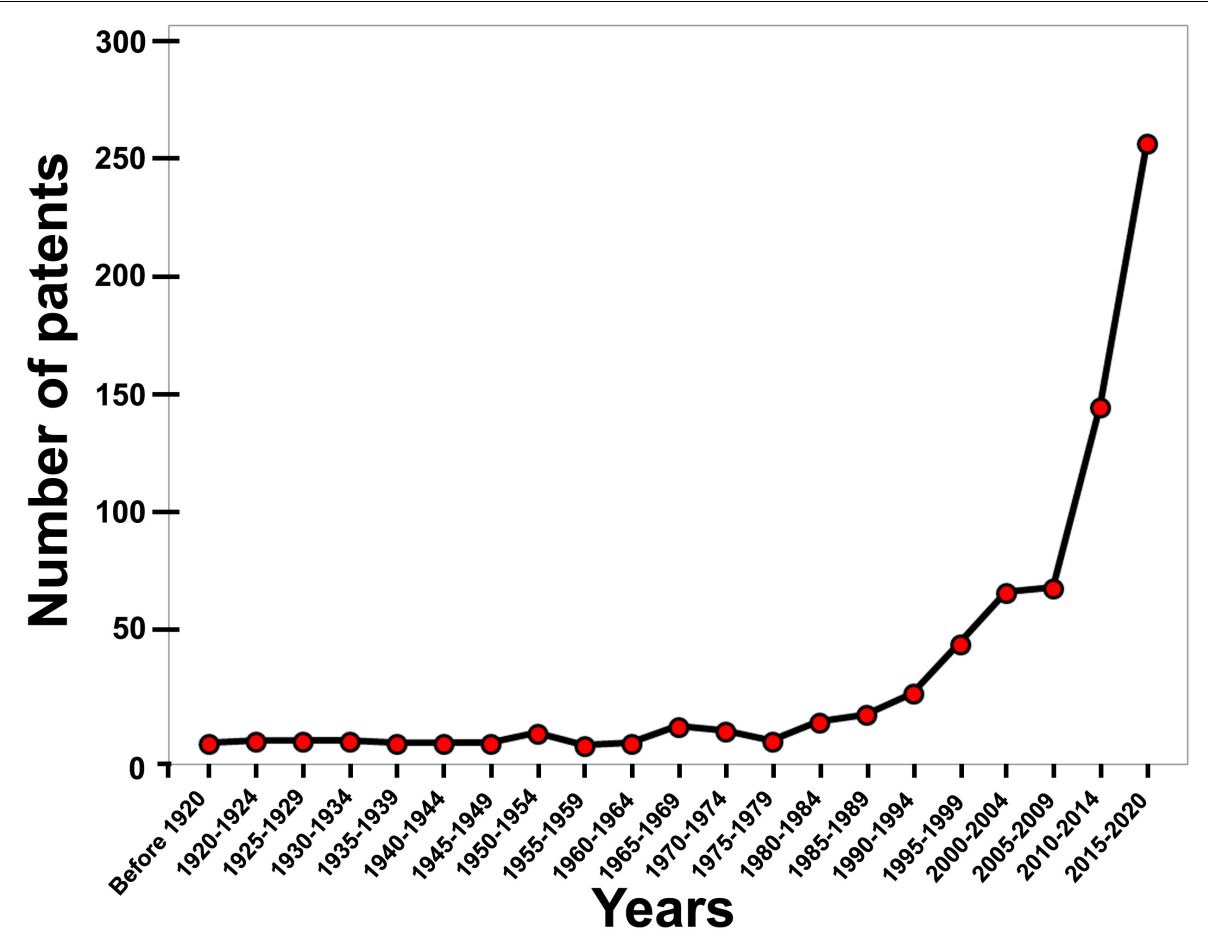

FIGURE 2 | Chronology for patents describing ES-related devices and methods in the last century. An exponential increase in patent numbers in the last two decades is apparent (Data derived from the Google patent research engine).

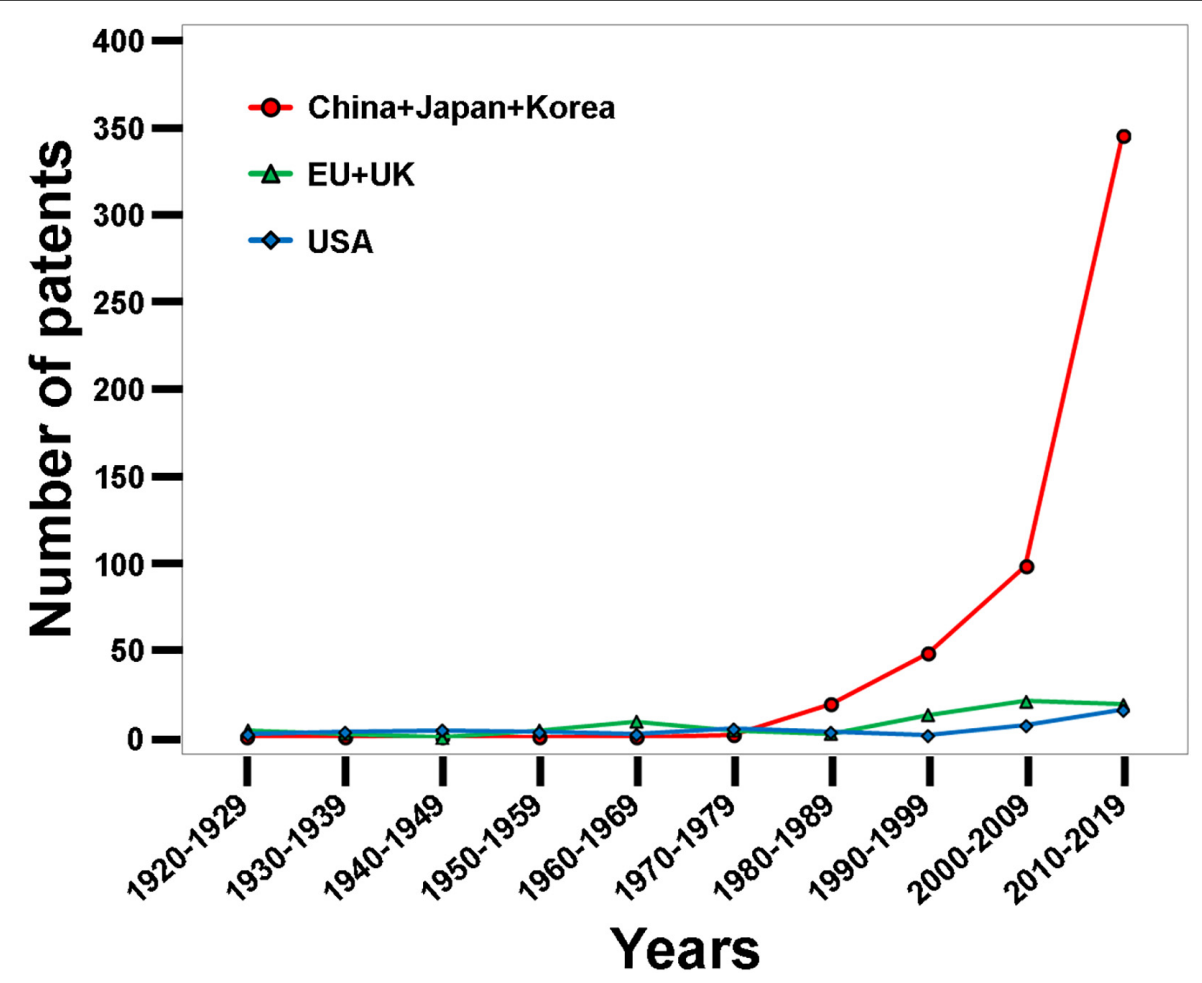

FIGURE 3 | Geographic distribution of ES patents in the last century amongst different countries, showing the recent dramatic output from Asian countries (China, Japan, Korea, and Taiwan), which is responsible for the observed exponential increase in patent numbers over the last two decades (Data derived from the Google patent research engine). 


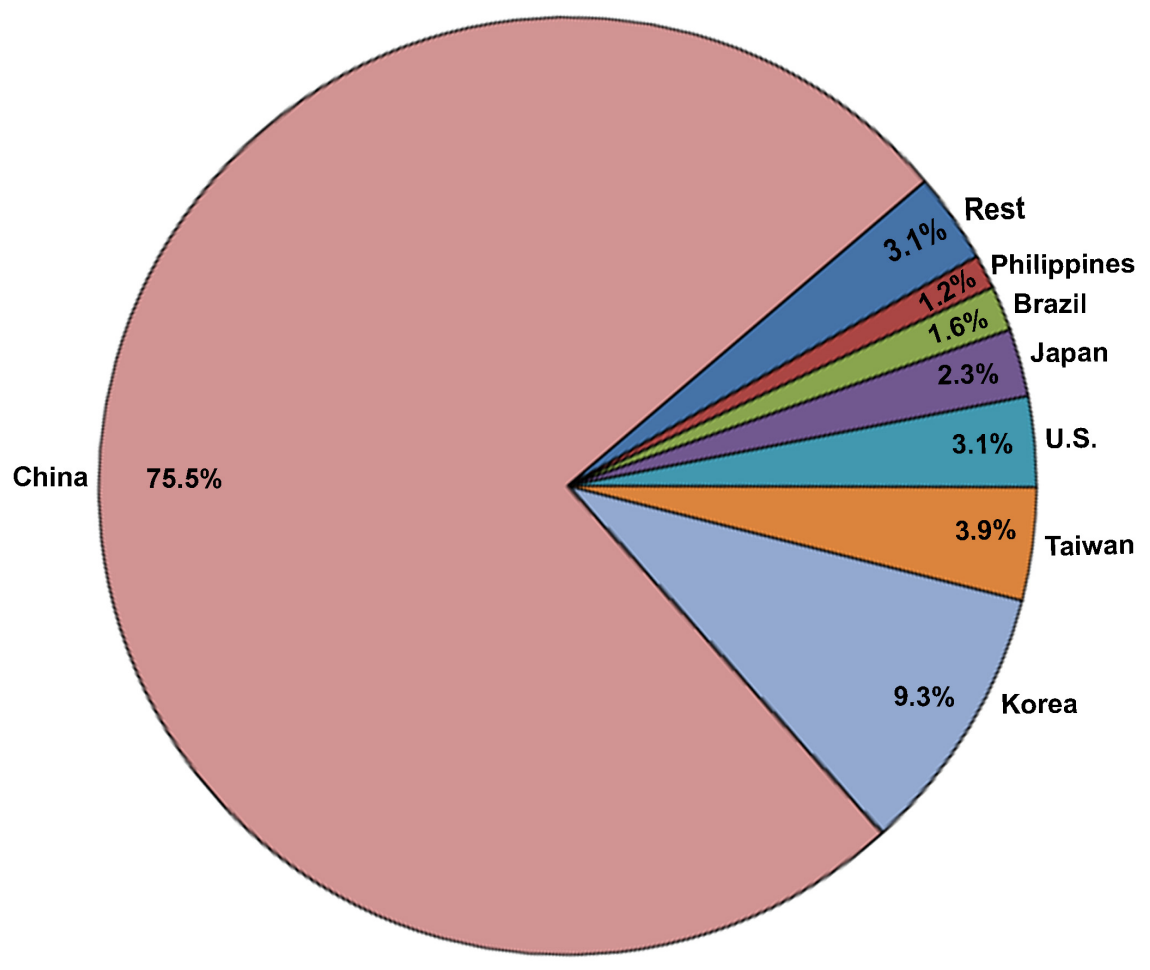

FIGURE 4 | Pie chart showing the geographic distribution of ES-related patents between 2015 and 2020 amongst different countries (Data derived from the Google patent research engine).

source of calcium supplement for animal feed and human health (Schaafsma et al., 2000; Lewicka et al., 2020). Moreover, the calcium extraction efficiency from oyster shell waste was shown to be lower than that from ES (Chakraborty and Gaonkar, 2016). Over the past decades, different methods have been developed to obtain calcium citrate or calcium chloride from ES (Waheed et al., 2019), making it an attractive raw material for the supplement market.

Calcium oxide $(\mathrm{CaO})$, also known as lime or quicklime, can be derived from the calcination of ES. $\mathrm{CaO}$ is utilized as a neutralizing agent in the agricultural, petrochemical, cosmetics, pharmaceutical, animal feed and tanning industries, or as a filler for aluminum, plastics, cement, glass, and paper [Other Industrial Consumers \& Manufacturing - EuLA: European Lime Association. EuLA (2020)]. These sectors provide a considerable market for ES upcycling. Quicklime was valued at about \$124 per ton in 2019 [USGS Online Publications Directory| Lime. USGS (2020)]. Different type of glasses, such as household and crystal glass, flat glass, and typical container glass, contain approximately 5 to $12 \% \mathrm{CaO}$ (Lewicka et al., 2020), and their production is a potential market for ES.

\section{Commercially-Available Eggshell-Based Products}

The calcium supplement market is an attractive sector for applications of ES waste. Bone Health Original ${ }^{\mathrm{TM}}$ capsules target bone heath, and advertise ES as an easily digestible, superior source of calcium (Bone Health Original). Similarly, OVOCET ${ }^{\circledR}$ is a product based on ES, as a supplementary source of highly absorbable calcium for both human and animal consumption (EGGNOVO). Eggshell Calcium Supplement ${ }^{\mathrm{TM}}$ (irRAW sistible) is another ES-based health product developed for the pet industry. Finally, Cluster Buster ${ }^{\circledR}$ is advertised as an eco-friendly lightweight powder made from egg shell to capture flies. Insects sink in this patented powder (POWDER TRAP ${ }^{\circledR}$ ).

\section{INTELLECTUAL LANDSCAPE OF EGGSHELL WASTE APPLICATIONS}

For this review, the Google patent research engine was utilized to identify global patents pertaining to ES in the last century (starting from 1920), and was searched using "eggshell" as a keyword. We observed that the annual number of ES patents was relatively stable and increased slowly over many decades; however, an exponential growth in patent numbers was observed during the last two decades (Figure 2). Overall, 673 patents pertaining to ES were granted in the last century. Of these patents, $536(80 \%)$ were issued in the last two decades. The large leap in the last two decades was mainly due to a remarkable increase in the number of patents originating from Asian countries including China, Korea, Japan, and Taiwan (Figure 3). Interestingly, around 40\% (257 patents) of these 673 patents were granted between 2015 and 2020 and address different biotechnological applications of ES. Around 40\% (99 patents) 
of the patents published between 2015 and 2020 represent biotechnological applications of ES, while about 60\% (158 patents) describe engineering technologies for the screening, separation and processing of ES. Recent advances in engineering technology patents are discussed in detail in the accompanying article (Ahmed et al., 2021). The main countries of origin of biotechnological patents were China (75.5\%), Korea (9.3\%), Taiwan (3.9), and the United States (3.1\%; Figure 4). The dramatic increase in the number of patents that diversify the applications of ES reflects the interests of investors and researchers to exploit eggshell waste generated by breaker plants. This review sheds light on the most recent patents published between 2015 and 2020 for different biotechnological applications of ES (Table 1).

\section{PATENTED BIOTECHNOLOGICAL APPLICATIONS FOR EGGSHELL}

\section{Biomedical Technologies}

Eggshell can be used as a source of medical calcium tonic and food additives including calcium lactate, calcium propionate, calcium gluconate, calcium citrate, and calcium acetate (Ran et al., 2018).

\section{Production of Calcium Lactate}

Calcium Lactate is widely used in the food industry as a curing, flavoring, leavening, and antimicrobial additive (Huang et al., 2019), in addition to its properties as a stabilizer, seasoning, and calcium-nutrition intensifying agent (Chen et al., 2019). The conversion of ES calcium into calcium lactate improves its solubility and absorption. New methods to prepare calcium lactate from ES have been patented to overcome the problems related to traditional calcination and acid-base neutralization methods (Chen et al., 2019).

During the last 5 years, many inventions have proposed microbial fermentation methods to produce calcium lactate from ES (Ma et al., 2015; Shao, 2017; Chen et al., 2019; Huang et al., 2019; Ma and Zhao, 2019). One method uses enzymatic hydrolysis and bacterial fermentation to produce lactic acid from ES. Firstly, powdered ES is converted to liquid through steps of heating and pressure homogenization, followed by treatment with papain to hydrolyze protein impurities. Following enzymatic hydrolysis, glucose and a combination of Lactobacillus acidophilus (L. acidophilus) and Lactobacillus bulgaricus (L. bulgaricus) is added to ferment the enzymolyzed ES liquid, which produces organic calcium. The extraction rate is claimed to reach $86 \%$, with $93 \%$ calcium lactate and 5\% calcium gluconate (Shao, 2017). Another invention proposes treatment of ES liquid with a mixture of enzymes (alkaline protease, neutral protease, and papain) to hydrolyze the proteinaceous impurities. Enzymolyzed ES liquid is mixed with glucose, and fermentation is initiated with a high-yield lactic acid-producing bacterium (Enterococcus mundtii, E. mundtii). Calcium lactate is precipitated with calcium hydroxide, purified, and crystallized (Chen et al., 2019). Another patented claim proposes the production of lactic acid from ES without a protease treatment step. Fermentation is carried out by E. mundtii in the presence of glucose followed by purification and crystallization steps. The purity of the produced calcium lactate is $99.25 \%$, resulting in $2.5 \mathrm{~kg}$ calcium lactate/kg ES (Ma et al., 2015). Another strategy uses four strains of lactic acid bacteria including E. mundtii, Streptococcus thermophilus (S. thermophilus), Lactobacillus casei (L. casei), and L. Bulgaricus to ferment ES in the presence of glucose, with a calcium lactate yield of $40 \mathrm{~g} / \mathrm{L}$ and purity of $93 \%$ (Huang et al., 2019). Improvements for the ES fermentation strategy have utilized immobilized cell technology, with E. mundtii embedded in sodium alginate. This immobilization strategy results in improved bacterial cell concentration, decreased fermentation time, and increased bacterial tolerance to $\mathrm{pH}$, temperature, and organic solvents (Ma and Zhao, 2019). Calcium lactate production using microbial fermentation is cost-effective, environmentally friendly, and eliminates the need for the powerconsuming calcination process (Ma et al., 2015).

\section{Production of Calcium Phosphate}

Tri-calcium phosphate $(\beta-\mathrm{TCP})$ and HAP are two forms of calcium phosphate that have been widely utilized as biocompatible materials (Lee et al., 2016; Lee and Kang, 2017). HAP is an essential mineral which makes up hard tissues in the human body, such as bones and teeth (Lee et al., 2016; Lee and Kang, 2018). Calcium phosphate can be produced from ES via calcination at $950-1,050^{\circ} \mathrm{C}$, followed by mixing with isopropyl alcohol and phosphoric acid. HAP, TCP, or a combination of both, are produced depending on the molar ratio of calcinated ES to phosphoric acid. The resultant calcium phosphate is ballmilled and heat treated, for applications in fabrication of artificial bone constructs (Lee, 2018). Similarily, pulverized and calcinated ES can be utilized as a starting material in combination with phosphoric acid to create HAP and TCP (Quina et al., 2017). The crystal phase and particle shape of the produced calcium phosphate can be modulated by controlling the phosphoric acid concentration, final solution $\mathrm{pH}$ and reaction temperature (Lee et al., 2016; Lee and Kang, 2017). Alternatively, calcium phosphate-based material can be produced using nano-sized calcinated ES powder and phosphoric acid-ammonia solution (Lee and Kang, 2018).

\section{Health-Related Products \\ Human}

Powdered ES is a rich source of "biological" calcium for oral dietary supplements that are proposed to increase bone density and treat age-related bone loss. In one application, Manuka Honey and lemon are added to ES powder to improve taste and smell and to enrich the final nutritional value of the calcium supplement (Shagdar and Myagmar, 2017).

Eggshell is the basis for a composite wound dressing for skin ulcers. ES, in combination with shell from litchi, peanuts, broad beans, and sesame, is treated with an enzyme mixture (1\% Protease, $5 \%$ amylase, and $2 \%$ pectase). The enzyme hydrolysate is steam sterilized, fermented using Bacillus subtilis (B. subtilis), and filtered to obtain an extract based on plant material and ES. Finally, the extract is mixed with chitosan and alginate and electrospun to form a composite wound dressing with low 
TABLE 1 | Roadmap for the review.

1. INTRODUCTION
2. INTELLECTUAL LANDSCAPE of EGGSHELL WASTE APPLICATIONS 3. BIOTECHNOLOGICAL APPLICATIONS of EGGSHELL

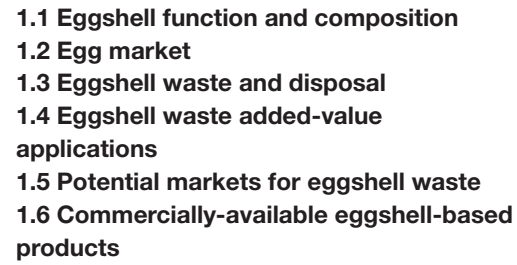

3.1 Biomedical technologies

3.2 Chemical technologies

3.3 Engineering technologies

3.4 Environmental technologies
3.1.1 Production of calcium Lactate

3.1.2 Production of Calcium Phosphate

3.1.3 Health-promoting products

3.1.3.1 Human

3.1.3.2 Animal

3.2.1 Plant growth promoters (fertilizer applications)

3.2.2 Food processing and production

3.2.3 Active calcium source

3.2.4 Active carbon source

3.2.5 Soluble protein source

3.2.6 Organic calcium source

3.2.7 Ultrafine active $\mathrm{CaCO}_{3}$ source

3.2.8 Biodiesel oil catalysis

3.2.9 Eggshell as component of plastic

3.3.1 Material Engineering

3.3.2 Nanoparticle (NP) production

3.4.1 Adsorption of heavy metals

3.4.2 Adsorption of organic compound

3.4.3 Adsorption of total nitrogen,

fluoride, and phosphate

3.4.4 Adsorption of soil pollutants

3.4.5 Adsorption of radioactive metal

3.4.6 Solubilization of sludge

3.4.7 Production of biomass

3.4.8 Magnetic ES adsorbent

\section{RECENT RESEARCH ACTIVITIES of EGGSHELL \\ 5. CONCLUSION and PROSPECTS}

production cost, good degradability, easy absorption, and good air permeability (Ye et al., 2019).

Chelated calcium can be prepared via an ES crushing strategy, which involves ES cleaning with sodium hypochlorite followed by drying and pulverization steps. The pulverized ES is dissolved in $15 \% \mathrm{HCl}$, and adjusted to $\mathrm{pH} 4$ using $\mathrm{NaOH}$. Solubilized proteins constituents are precipitated with phosphorylated corn starch flocculant and removed using centrifugation or filtration. The clear supernatant is mixed with either glycine or yeast, to form glycine-chelated or yeast-chelated calcium with a purity of $98 \%$, for use in health care products and as food additives (Yang and Shen, 2017).

Eggshell-derived activated $\mathrm{CaCO}_{3}$ possesses excellent dispersibility and affinity for use as an incremental filler. ES is crushed, sieved, and mixed with water and stearamide before freeze-drying. The resulting ES powder is combined with starch, calcium silicate, calcium sulfate whiskers, calcium carbonate, lanolin, lecithin, trisodium citrate, sodium bifluoride, and then dried to obtain a compound calcium carbonate powder. The final step involves spraying this powder evenly with stearic acid (Wang, 2015a).

Eggshell-derived skin products have applications for whitening, exfoliating and moisturizing applications. Regarding skin cleansing products, soft beads made of polypropylene and polyethylene have raised environmental and skin safety concerns; therefore, ES powder has utility as a replacement for soft beads as a facial cleanser (Zhang, 2018).

\section{Animal}

Eggshell has applications as a calcium source in animal feed. Washed ES can be dried at $70-75^{\circ} \mathrm{C}$, and ground (Urlovskis et al., 2016). Laying hens require calcium particles in their diet to maintain high rates of egg production. ES is incorporated in the layer feed to improve the bird health, increase egg production 
and maintain high eggshell quality (Li, 2017). ES powder is also used as a component of lobster feed to replace more expensive calcium-containing raw materials. Dried ES is cleaned, crushed, and sieved, followed by wetting with water, to be mixed with lobster feed at a ratio of 1:10 to 1:20 (Jin, 2018).

\section{Chemical Technologies}

\section{Plant Growth Promoters (Fertilizer Applications)}

Calcium plays a vital role in plant growth. However, most inorganic calcium salts, including $\mathrm{CaCO}_{3}$, have low solubility in water and therefore exhibit unsatisfactory efficiency of uptake. Five (5) patents comprising new methods that convert ES-derived $\mathrm{CaCO}_{3}$ to useful soil fertilizers with improved calcium solubility have been issued recently (Liu et al., 2015; Capoani, 2016; Kim et al., 2018; Zhao and Wang, 2019; Yang et al., 2019d). ES can be converted to liquid calcium acetate fertilizer via the reaction of pulverized ES with acetic acid. As calcium acetate is relatively neutral (0.2 M solution is $\mathrm{pH} 7.6)$, it does not acidify soil when used as an amendment (Zhao and Wang, 2019). Dry, ground ES can be mixed with peanut bran, livestock and poultry manure, organic waste, and sprayed with microbial inoculants to produce a safe, environmentally friendly, and efficient fertilizer (Liu et al., 2015). Similarily, ES waste contaminated with ESM, EW, and EY can be treated and dissolved to produce a natural liquid fertilizer with improved solubility. In this process, ES is crushed and mixed with protease and a mixture of organic acids (acetic, malic, lactic, succinic, and citric acids) to decompose and ferment the proteinaceous contents. The organic acids react with ES to produce water-soluble calcium (Kim et al., 2018). Another approach, using marine shell extract, ES powder, and fermentation microbial agents, produces a fertilizer supplement for apple orchard cultivation. A mixture of ground abalone, oyster, and shellfish shells with calcinated ES improves apple fruit tree productivity and prevents disease (Yang et al., 2019d). Another fertilizer, produced from poultry manure and ES, is economic, environmentally friendly, and possesses high calcium and nitrogen content (Capoani, 2016).

\section{Food Processing and Production}

Eggshell has a wide range of applications in the food industry and in food production. Calcium-supplemented noodles can be prepared with incorporation of cleaned, disinfected, and sieved ES powder, which are claimed to be tasty and possess high nutritional value (Xie, 2018; Zeng, 2019). Organic calcium salts possess higher solubility and bio-availability than ESderived calcium carbonate. An invention describes a method of preparation of sausage which contains a mixture of calcium acetate - calcium citrate derived from ES powder. The ES is cleaned, dried and ground, and added to a solution containing acetic and citric acids. The acetate-citrate composite calcium precipitate is dried and incorporated into the process of making sausage. The product provides a meat foodstuff which is enriched with readily absorbed dietary calcium (Liu et al., 2018). A cupcake with higher nutritional value can be prepared with ES mixed with standard ingredients (Giango et al., 2017). Cleaned ES powder can be mixed with crushed rice and fruit peel to produce a delicious wine beverage with high nutritional value (Wang et al., 2016).

Calcium propionate is used in the food industry as a preservative due to its antimicrobial activity against molds, aerobic bacilli, and gram-negative bacteria. In addition, it is readily absorbed in the GI tract and can provide essential calcium. A patent discloses a method to produce calcium propionate from ES as raw material. ES is cleaned, crushed, and sieved to obtain fine powder. The formed powder is solubilized in propionic acid, filtered and dried to produce soluble white scaly calcium propionate crystals with a purity of $98.5 \%$ (Wang, 2015b).

\section{Active Calcium Source}

Calcium oxide is usually made by the thermal decomposition of calcium carbonate materials, such as limestone, seashells, or ES. Calcium hydroxide, also called slaked lime, $\mathrm{Ca}(\mathrm{OH})_{2}$, is obtained by the action of water on $\mathrm{CaO}$. However, it is difficult to obtain highly active $\mathrm{Ca}(\mathrm{OH})_{2}$ using this strategy. A patent reports the use of pulverized ES to produce highly active porous $\mathrm{Ca}(\mathrm{OH})_{2}$. ES powder, calcinated at $650-750^{\circ} \mathrm{C}$ under negative pressure $(-80$ to $-50 \mathrm{KPa})$, is reacted with air or oxygen to obtain highly porous $\mathrm{CaO}$ powder. The superfine $\mathrm{CaO}$ is enclosed in a $\mathrm{CO}_{2}$-free space with humidity of 90$95 \%$ to produce a highly active porous $\mathrm{Ca}(\mathrm{OH})_{2}$ with activity degree $>400$, whiteness $>90$, and surface area $>25 \mathrm{~m}^{2} / \mathrm{g}$ (Wang P. et al., 2019). Similarly, an ES-based porous $\mathrm{CaO}$ solid alkali can be produced using a simple and cost-effective temperature programmed ES roasting strategy. Pulverized ES is calcinated at $600-1,000^{\circ} \mathrm{C}$ to produce a solid alkali with abundant pores, high catalytic activity and a large specific surface area (Ding, 2018). Another method involves cleaning and disinfecting the fresh ES followed by stripping treatment and drying. Dried ES is crushed, sieved, and calcinated at $300-1,500^{\circ} \mathrm{C}$ to obtain calcinated ES powder (Yang, 2015). ES can be used as a natural ingredient in soap to overcome the problem of toxicity to human skin caused by conventional chemical compounds. The ES is dried at 100$200^{\circ} \mathrm{C}$, pulverized and mixed with soap base. This natural soap product has cleaning, antibacterial and moisturizing abilities that render it suitable as a laundry or kitchen detergent, or as a personal beauty soap (Kang, 2016). As fruits and vegetables often have residues of pesticides and fertilizers, an invention utilizes ES to produce an abrasive scrubbing agent without the use of any additives. Pulverized ES is thermally decomposed into $\mathrm{CaO}$ through calcination at $950-1,100^{\circ} \mathrm{C}$. The cooked ES $(\mathrm{CaO})$ is then crushed, sieved, and mixed with fresh ES powder and bran powder to produce a very efficient, non-toxic, and harmless fruit and vegetable cleaning agent (Wang S. et al., 2017; Figure 5).

\section{Active Carbon Source}

Activated carbon has a rich pore structure and a high specific surface area. Adsorption based on activated carbon is widely used in the fields of raw material production for refining air and control of water pollution. A patented method uses powdered ES in combination with sucrose for the production of activated carbon. A mixture of ES powder with sucrose or glucose is calcinated at 800 or $1,100^{\circ} \mathrm{C}$, respectively. Calcination is performed under an inert atmosphere and the product is then 


\section{$\mathrm{ES}\left(\mathrm{CaCO}_{3}\right)$}

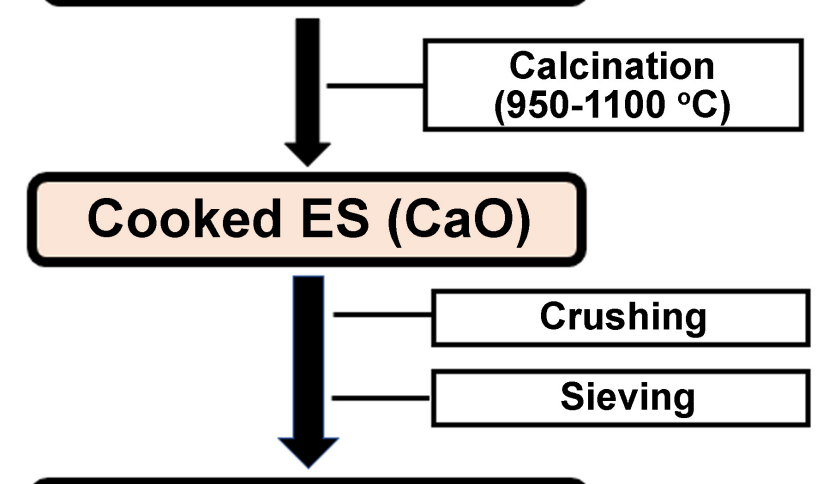

\section{ES powder $(\mathrm{CaO})$}

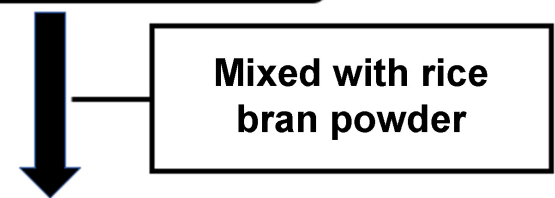

\section{Fruit \& vegetable cleaning agent}

FIGURE 5 | Schematic presentation of patent CN107057890A describing a method to prepare a cleaning agent for fruits and vegetables based on calcinated ES powder.

pickled using hydrochloric acid $(\mathrm{HCl})$ to obtain activated carbon (Shi et al., 2019). The process of graphene synthesis consumes huge amounts of calcium carbonate. A disclosed patent describes the production of graphene using ES as a replacement for calcium carbonate, therefore reducing the industrial costs while carrying out mass production with simple equipment and operation. The process involves mixing ES with a reducing agent to obtain a powder which is then combusted under atmospheric conditions to produce a crude powder. Graphene is obtained by pickling the crude powder using $\mathrm{HCl}$, followed by washing and filtration. The resulting graphene is a superior capacitor material. This approach requires a short reaction time and saves energy as it utilizes the energy released by the combustion reaction itself (Wang L. et al., 2019).

\section{Soluble Protein Source}

The organic matrix (3.5\% of the ES) consists of proteins and proteoglycans which may possess valuable bioactive properties. Following removal of the outer cuticle and inner ESM with ethylenediaminetetraacetic acid, the cleaned ES powder is demineralized using acetic acid (2-23\%), followed by centrifugation to separate the acid-insoluble organic matrix. The main advantage of this approach is the low concentration of the weak acid that does not degrade the organic matrix constituents.
Moreover, the water solubility of acetic acid facilitates its removal in subsequent purification steps (Liu, 2017). Another invention discloses a method for co-purifying three abundant ES matrix proteins [ovocleidin-17 (OC-17), ovocleidin-116 (OC-116), and ovocalyxin-36 (OCX-36)] from ES by a combination of anionic and cationic exchange chromatography in phosphate buffer. This efficient co-purification of OC-17, OC-116, and OCX-36 achieves high purity (>90\%; Ma et al., 2017).

\section{Organic Calcium Source}

Calcium citrate is a good source of calcium for dietary supplements, due to its high calcium content, high absorptivity, good solubility, low heavy metal content, and good ionic stability. Moreover, it does not interfere with the absorption of other critical ions including iron. A patent reports a method to produce calcium citrate from ES. Pre-heated ES powder is suspended in acetic acid to produce calcium acetate solution, which is then mixed with citric acid to produce calcium citrate. The invention also formulated a chewable tablet through the combination of calcium citrate with other additives including vitamin D (Zhu et al., 2016). Another invention describes the production of water-soluble ES calcium powder or liquid. ES is calcinated in an electric heating furnace at a temperature of 900 to $1,200^{\circ} \mathrm{C}$. The purified calcinated ES is suspended in acetic acid (4$30 \%)$, converted into ionic organic calcium, and then dried and pulverized to produce water-soluble ES calcium acetate powder, which is rich in organic acids and 7 essential amino acids (Hyun, 2015).

\section{Ultrafine Active $\mathrm{CaCO}_{3}$ Source}

Calcium carbonate is widely used also in food production, medical fields, and chemical industries. An invention claims the preparation of an ultrafine active calcium carbonate from ES. After ESM removal, pulverized ES with particle sizes of 0.1$10 \mu \mathrm{m}$ was mixed with water and a polysaccharide (starch, dextran, chitosan, or pectin), followed by freeze-drying. The edible polysaccharide is a hydrophilic modifier to activate ultrafine calcium carbonate (Ma et al., 2016).

\section{Biodiesel Oil Catalysis}

A patented invention describes a preparative method for modified ES biodiesel catalyst, involving drying and crushing steps to obtain ES powder, which is then immersed and roasted with sodium hydroxide and sodium nitrate to effectively increase its alkaline and acidic active groups. This greatly improves ES catalytic activity for preparation of biodiesel, with a high number of recycling cycles. Moreover, the conversion rate of catalytically produced biodiesel is high (Xiang et al., 2018).

\section{Eggshell as Component of Plastic}

A patented invention describes a method to prepare a resin composition comprising ES powder (5 to 50 parts) and high molecular polymer (100 parts). ES undergoes various processing steps including washing, ESM removing, drying, and pulverization. The high molecular polymer can be meltkneaded with ES powder $(150 \mu \mathrm{m})$ at a temperature below $200^{\circ} \mathrm{C}$. The resin composition is described as an environmentally friendly material that can be used for packaging (Li, 2018). 
Another patented method mixes ES powder with polylactic acid to fabricate green packaging material (Li, 2020). Similarily, ES in combination with polylactic acid was patented for the production of packaging boxes with improved heat insulating ability ( $\mathrm{Li}$, 2019). In addition, ES powder has been patented as a raw material for the production of biodegradable plastic with improved degradability, flexibility and tensile strength (Wang and Song, 2015). Furthermore, a biopolymer blend containing engineered proteinaceous ES nanopowder can produce biopolymeric film with enhanced thermal stability, tensile strength and improved durability for the fabrication of food, waste, and biomedical packaging (Rangari and Tiimob, 2019).

\section{Engineering Technologies Material Engineering}

The grinding process to produce powdered materials in many fields, such as building materials, chemical industry, mining, and ceramics, grinding aids are used to increase the efficiency and output of the mill while maintaining the original material quality standards. A patent claims the use of ES powder as a grinding aid material, where ES is ground, sieved, moistened with water and mixed with the cement during milling. Use of the ES-based grinding aid reduced water consumption during milling and increased the product mechanical properties (Wang B. et al., 2019). ES can be also applied to architectural materials. A patented process claims the utilization of pulverized ES as a cement extender through mixing with ordinary sand, cement and water to produce a hollow block (Lagumen and Colmo, 2016). A similar patented process describes a strategy to produce porous building insulation material from ES and glass waste, which has low density, uniform pore size, high strength and good thermal insulation capacity. Briefly, pulverized ES as a foaming material is mixed with glass waste and heated at $800-1,000^{\circ} \mathrm{C}$ (Tian, 2015). Another patent describes the dissolution of ES in aqua regia/isopropyl alcohol solution to produce a $\mathrm{CaCO}_{3} / \mathrm{CaO}$ solution that is then mixed with $85 \%$ phosphoric acid $\left(\mathrm{H}_{3} \mathrm{PO}_{4}\right)$ to form calcium phosphate glass precursor solution. This solution is heated at $800^{\circ} \mathrm{C}$ for three hrs to produce calcium phosphate glass that exhibits similar physical properties and better biocompatibility, as compared to traditional phosphate-based glass. The enhanced biocompatibility of ES-based glass is due to the presence of calcium (Lee and Kang, 2019). Furthermore, a patented process describes a sustainable approach to produce calcium silicate through the combination of pulverized ES, as a calcium source, with red ceramic chamote as the silicone source. The high temperature solid state reaction of this mixture at $1,000-1,100^{\circ} \mathrm{C}$ produced calcium silicate material with properties comparable to traditional calcium silicate materials that could be utilized as a ceramic material for thermal insulation (Guedes et al., 2016). Another patent reports a strategy to produce woodplastic material using ES in combination with polypropylene, polyethylene grafted maleic anhydride, ethylene-vinyl acetate copolymer, nano-titanium dioxide, glass fiber, wood flour, silane coupling agent, and flame retardant. This wood-plastic material has excellent heat resistance, compression resistance and tensile resistance (Cao, 2018).
Interestingly, a disclosed patent describes the melting and binding of a homogenous mixture of polycaprolactone, polybutylene succinate, and ES powder at $120-190^{\circ} \mathrm{C}$ to produce a composite plastic material with superior tensile strength, modulus and elongation at break, that can be utilized in fabrication of toys, packaging, and in the electronics industry ( $\mathrm{Li}$ et al., 2015). An ES powder-based synthetic paper preparation method involves the combination of powdered ES with a formulated polyurethane solution. ES as a biomass resource replaces the use of $\mathrm{CaCO}_{3}$ in the production of synthetic paper, and reduces the exploitation of natural resources and the environmental burden of mining (Wang D. et al., 2017). Finally, a dust-free chalk strategy involves the utilization of ES powder as a replacement for non-renewable gypsum resources. The dustless chalk described herein showed improved stability (Zhou et al., 2019).

\section{Nanoparticle Production}

The inherent pore structure of calcitic avian ES makes it an ideal natural scaffold for the production of nanoparticles (NPs; Yang et al., 2019c). $\mathrm{CaCO}_{3}$ constitutes about 95\% of ES weight (Hincke et al., 2012; Neunzehn et al., 2015; Ahmed et al., 2019a), and has been used to produce $\mathrm{Ca}(\mathrm{OH})_{2}$ NPs. Pulverized ES is dissolved in $\mathrm{HCl}(8-15 \%)$, followed by filtration, and mixing with $\mathrm{NaOH}(10-15 \mathrm{M})$. The precipitated $\mathrm{Ca}(\mathrm{OH})_{2}$ is washed in water and oven dried at $100-150^{\circ} \mathrm{C}$ to produce $\mathrm{Ca}(\mathrm{OH})_{2}$ NPs having a $\mathrm{CaO}$ content of $96-99 \%$ and a particle size in the range of 0.01 to $0.1 \mu \mathrm{m}$. $\mathrm{Ca}(\mathrm{OH})_{2} \mathrm{NPs}$ are used as an additive in inorganic binders to improve their reactivity and/or to develop high-performance mechanical properties (Panait et al., 2020; Figure 6). In addition, a patent disclosed a strategy to produce $\mathrm{CaCO}_{3}$-silver (Ag) NPs using ES as a template. ES is pulverized and loaded with $\mathrm{Ag}$ ions, followed by heating at $400-600^{\circ} \mathrm{C}$. The resultant $\mathrm{CaCO}_{3}-\mathrm{Ag}$ NPs can be utilized for various applications including catalysis, tissue engineering, coatings, and production of antibacterial agents, pigments, and ceramics (Yang et al., 2017; Figure 7a). Another patented process demonstrates the production of copper sulfide $(\mathrm{CuS})$ NPs using ES as a template. ES is pulverized and loaded with copper and sulfide ions to generate CuS NPs that exhibit antimicrobial activities against Staphylococcus aureus (S. aureus; Yang et al., 2019c; Figure 7b). Similarily, a patent claims the use of ES powder as a biological carrier that adsorbs copper $(\mathrm{Cu})$ ions to form a complex copper nanomaterial. Cu NPs-loaded ES showed antibacterial activity against Escherichia coli (E. Coli) and S. aureus (Yang et al., 2019b).

Eggshell powder can serve as a template for the development of copper selenide-loaded ES NPs for catalytic degradation of organic pollutants in wastewater, such as 4-nitrophenol (Yang et al., 2019a). Alternatively, a patent disclosed a chemical process for the fabrication of iron (Fe)/ferrous sulfide (FeS)- loaded ES NPs, capable of degrading $>95 \%$ of 4-nitrophenol in wastewater (Yang et al., 2020). Similarly, pulverized ES loaded with Fe NPs can remove phosphorus from wastewater. Processing steps include treatment of ES with $\mathrm{HCl}$, pulverization, addition of ferric salt and $\mathrm{NaBH}_{4} / \mathrm{KBH}_{4}$ solutions, drying to obtain the magnetically stable and oxidation-resistant nano adsorbent. 


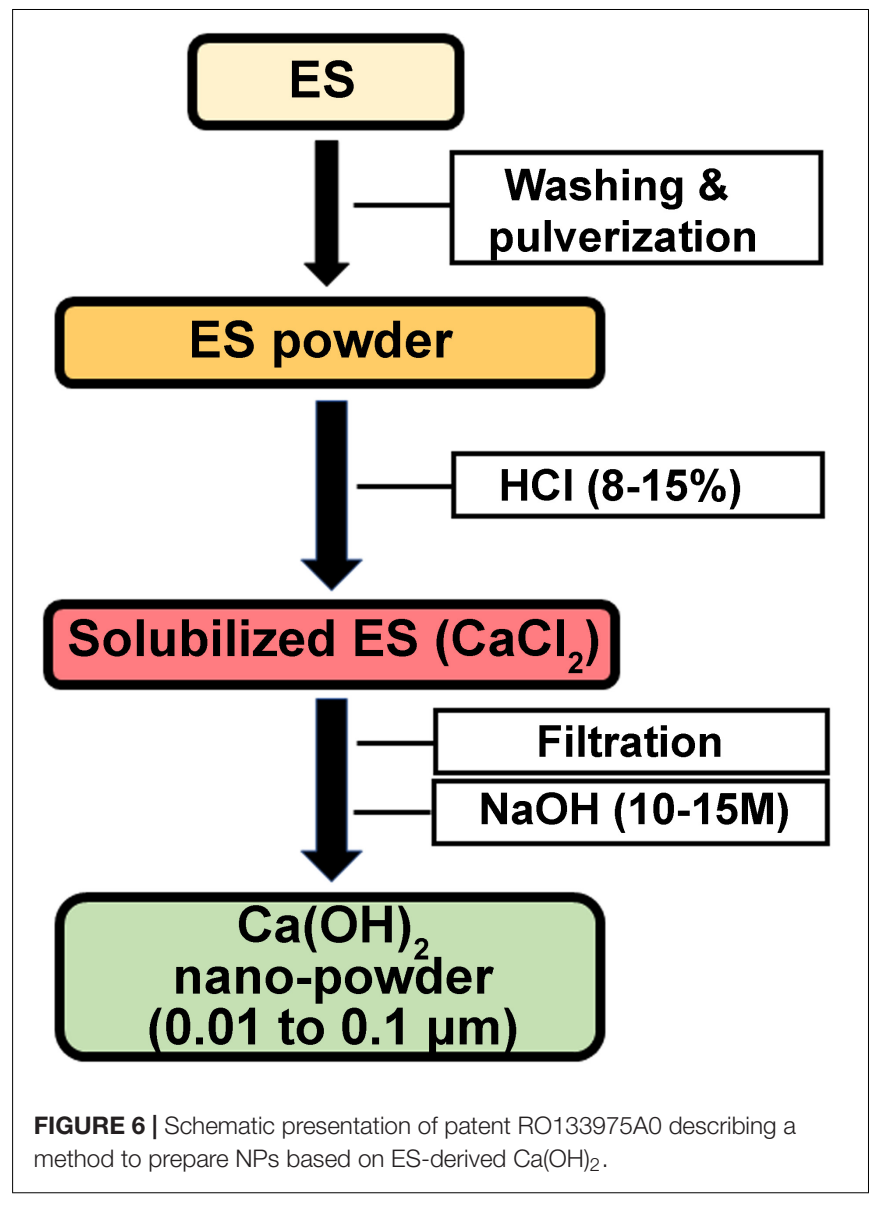

The iron NP-loaded ES exhibited > 99\% removal rate for phosphorus, and can be magnetically separated for easy recycling and regeneration (Xie et al., 2016).

\section{Environmental Technologies}

Eggshell can also be used as a natural environmentally friendly biosorbent for heavy metals, dyes, organics, sulfonates, and fluorides (Baláž, 2014; Ahmed et al., 2019a), due to its abundance, low cost, and easy processing. As a potential adsorbent, ES combines some important characteristics including fast adsorption rate, superior adsorption capacity, and high selectivity for heavy metal ions in industrial wastewater (Tian, 2014). In addition, calcination of ES increases its pore size and surface area, for improved removal capacity for heavy metals and neutralization ability for strongly acidic wastewater (Park et al., 2007).

\section{Adsorption of Heavy Metals}

A patented process for treating wastewater uses ES calcinated at $850-900^{\circ} \mathrm{C}$ that showed an efficiency of $90 \%$ for removal of $\mathrm{Cu}$, zinc $(\mathrm{Zn})$, arsenic (As), and chromium (Cr; He et al., 2018). The chemical modification of calcinated ES $\left(550^{\circ} \mathrm{C}\right)$ using silane coupling agent (KH-570) and tetraethyl orthosilicate leads to the formation of a promising adsorbent for $\mathrm{Cr}$ (VI) removal from industrial wastewater (Gao et al., 2017). Likewise, the aforementioned chemically-modified calcinated ES, in combination with carbonized rice straw and husk (produced at $400^{\circ} \mathrm{C}$ ), binds heavy metal ions such as $\mathrm{Cr}$ (Chen, 2017). A granular composite adsorbent, combining the clay mineral sericite (Binder) and heat-treated ES (200$900^{\circ} \mathrm{C}$ ), absorbs and removes the heavy metal lead ( $\mathrm{Pb} \mathrm{II}$ ) from wastewater. Sericite as a binder serves not only as a spherical adsorbent but also has a synergistic effect to increase the adsorption rate of ES for heavy metals, while ES also serves as a neutralizer for acidic industrial wastewater (Choi, 2020). ES-modified activated carbon composite filter removes As from wastewater. Calcium-loaded activated carbon powder is prepared by soaking ground ES in acetic acid to obtain soluble calcium which is mixed with activated carbon. The resultant calcium-loaded activated carbon powder is mixed with ground ESM, polyethylene resin, and pore-forming agent (sodium chloride) to produce a composite filter element to remove As from drinking water (Sun, 2017b). The combination of the previously prepared calcium liquid with phosphoric acidtreated carbon produces calcium- and phosphate- loaded carbon. The modified carbon is mixed with zeolite and pulverized ESM to produce a composite capable of removing heavy metal ions and organic pollutants from lithium battery industrial wastewater with high efficiency (Sun, 2017a). Chemically modified ES powder (cobalt chloride, $\gamma$-aminobutyric acid, thyme and

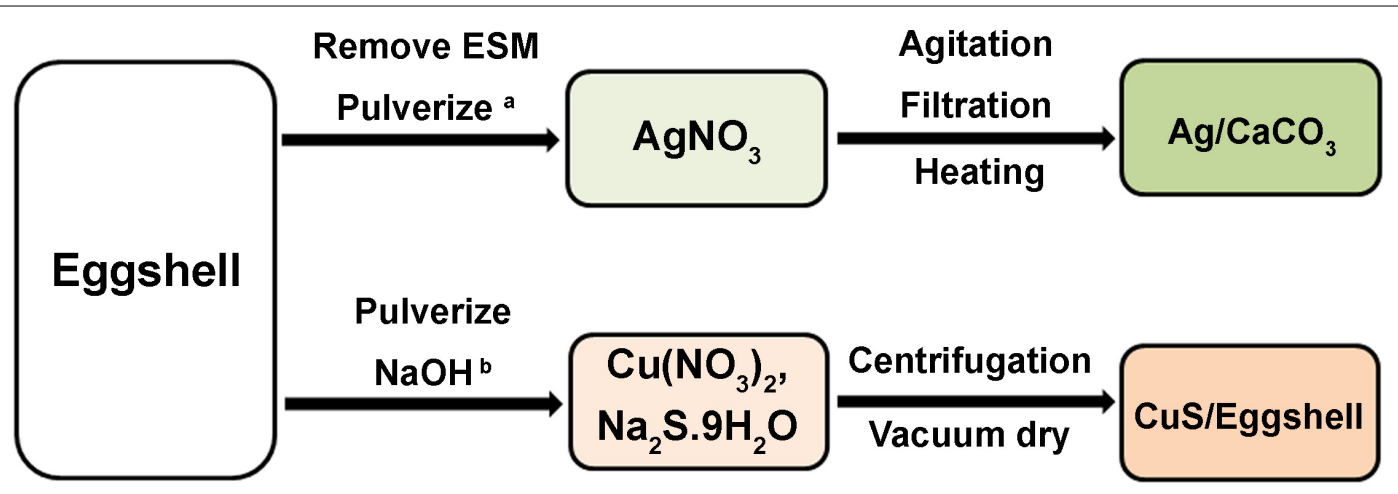

FIGURE 7 | Schematic presentation showing the production of ES-based nanoparticles. a: Ag/Eggshell (CN106862585A), and b: CuS/Eggshell (CN109809466A). 
rhododendron extract, and isooctyl ferulate) efficiently removes cyanide $\left(\mathrm{CN}^{-}\right), \mathrm{Cr}(\mathrm{VI}), \mathrm{Cu}(\mathrm{II}), \mathrm{Zn}$ (II), and nickel (Ni II) from electroplating wastewater and may serve as an additive for rapid drying paint (Chen, 2018). Finally, a strategy to purify acid mine drainage (AMD) using a fixed bed adsorption process based on pulverized ES as an adsorbent has great potential to remove heavy metal including cadmium (Cd II), $\mathrm{Pb}$ (II), and $\mathrm{Cu}$ (II) from AMD. The discharge after adsorption meets water quality standards suitable for agricultural irrigation (Lu et al., 2016).

\section{Adsorption of Organic Compounds}

Avian ES is a potential adsorbent for removal of organic pollutants such as aromatic compounds that are present in many industrial wastewater effluents. The electrostatic nature of $\mathrm{CaCO}_{3}$ and its nanoporous structure make it a potential candidate for development of solid sorbents for the extraction of polycyclic aromatic hydrocarbons. Briefly, ES is treated with oxidizing agent, ground, and dissolved with $\mathrm{HCl}$. Calcium carbonate crystals containing a monomeric Vateritic structure can be grown from a solution of calcium carbonate using various strategies (Nuhu et al., 2015). Alternatively, zinc oxide (ZnO)-loaded ES has been patented as an adsorbent material for organic matter and the photocatalytic decomposition of organic matter. ES is mixed sequentially with solutions of coupling agent, $\mathrm{Zn}$ ions, and alkali, and microwaved to form stable $\mathrm{ZnO}$-loaded ES. The advantages of this invention are that the photocatalytic activity of $\mathrm{ZnO}$ is combined with the adsorption capacity of ESM to treat polluted water (Qiu et al., 2017).

\section{Adsorption of Total Nitrogen, Fluoride, and Phosphate}

Excessive nitrogen content is a key element in water pollution and eutrophication. Modified ES with a superior adsorption capacity for nitrogenous species to remove total nitrogen from wastewater can be prepared by combining pulverized ES with Fe (III) salt solution under the effect of heating $\left(50-75^{\circ} \mathrm{C}\right.$; $\mathrm{Li}$ and Yan, 2020). Another method describes the use of pulverized ES to prepare a water-purifying fluoride-removal agent. After treatment with phosphoric acid or phosphate solution, followed by heating, ES is converted into a water purification agent that is superior to the commercially available defluoridination material (hydroxyphosphate; Pan and Tang, 2020). Recently, ES calcinated at $700^{\circ} \mathrm{C}$ (CES700) served as an efficient, low-cost, and eco-friendly adsorbent to recover phosphate ions from liquid effluents in batch or fixed-bed processes. CES700 achieved an adsorption capacity of about

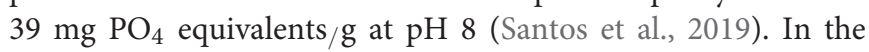
acidic range $(\mathrm{pH}<6)$, an adsorbent material produced with iron oxyhydroxide and calcined eggshell $\left(700^{\circ} \mathrm{C}\right)$ at a ratio of 1:0.5 (OFeCES.0.5) showed the best phosphate adsorption properties with a maximum adsorption capacity of $70 \mathrm{mg} \mathrm{PO}_{4}$ equivalents/g (Almeida et al., 2020).

\section{Adsorption of Soil Pollutants}

Eggshell adsorbent can be utilized for soil pollution control and agricultural remediation. Two patented processes claim the use of powdered ES as a soil conditioning agent for soil contaminated by heavy metals. ES powder is mixed with heavy metal-contaminated acidic farmland soil. ES absorbs heavy metals in the soil, and increases the soil $\mathrm{pH}$, leading to a reduction in the absorption of heavy metals by crops and an increase in crop quality and yield (Lu et al., 2017, 2018).

\section{Adsorption of Radioactive Metal}

Uranium-containing polluted wastewater is highly injurious to animal/human health due to its radioactivity and chemical toxicity. A patent claims a utilization of powdered ES as a uranium adsorbent, with a uranium removal rate of $88 \%$ (Huang et al., 2017).

\section{Solubilization of Sludge}

Excess sludge is a byproduct of biological wastewater treatment that mainly comprises microorganisms and their cell wall glycan strands, which is resistant to biodegradation (Lee et al., 2019). A patent discloses a process to solubilize sludge through combining ultrasonication with modified ES. Pulverized ES is calcinated at $700-900^{\circ} \mathrm{C}$ and soaked in sulfuric acid solution, followed by a second calcination step to produce modified ES. Ultrasonication greatly increases the cracking rate of sludge cells and effectively reduces the cracking time for the remaining sludge. This process breaks through the moisture content bottleneck for sludge that is difficult to reduce below $60 \%$ after cracking. The resultant treated sludge has no odor and does not require external heating energy after cracking (Xiang et al., 2019). A magnetic slow-release carbon source can be prepared using municipal sludge and ES as raw materials. Pulverized ES is mixed with superparamagnetic ferrite material to produce magnetic hydrotalcite scaffold material, which effectively solves the problem of difficult recycling of the material after use. Hydrotalcite is a layered double hydroxide of general formula $\mathrm{Mg}_{6} \mathrm{Al}_{2} \mathrm{CO}_{3}(\mathrm{OH})_{16} \cdot 4\left(\mathrm{H}_{2} \mathrm{O}\right)$. The magnetic hydrotalcite scaffold material is placed in the sludge fermentation broth, and the volatile acids that serve as a small molecule carbon source in the fermentation broth are adsorbed to obtain a magnetic slow-release carbon source (Yue et al., 2018).

\section{Production of Biomass}

A patent describes a method to remove heavy metals present in the soil and simultaneously obtain biomass, using a combination of pulverized ES and microalgae. This hybrid system is capable of purifying AMD through acid neutralization and heavy metal adsorption activity, along with microbial contaminant removal. The heavy metal removal rate for the patented ES-microalgae combination was $>95 \%$ for iron $(\mathrm{Fe}), \mathrm{Cu}, \mathrm{Zn}$, manganese $(\mathrm{Mn})$, and $\mathrm{Cd}$. Moreover, the microalgae can be utilized as a biological source of new biomass for biodiesel production (Choi, 2016a; Figure 8). Interestingly, ES has also been patented as a nutrient for growth of microalgal biomass (Choi, 2016b; Figure 8).

\section{Magnetic ES Adsorbent}

A method for preparing a modified ES magnetic adsorbent to effectively remove heavy metals from wastewater is disclosed. 


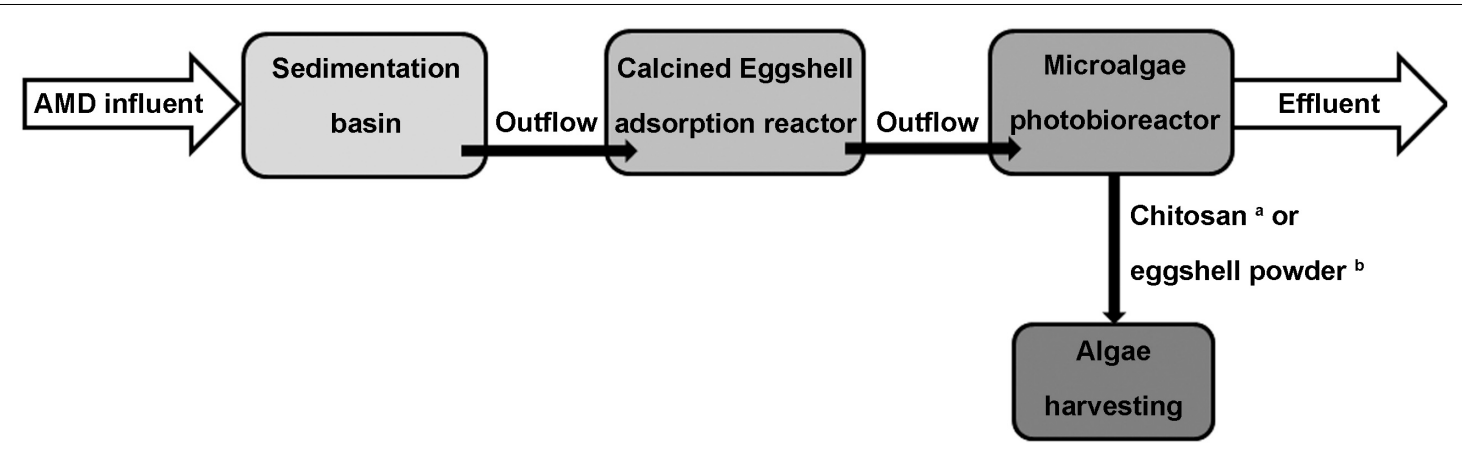

FIGURE 8 | Schematic presentation showing the utilization of ES for the production of biomass. a: Acid Mine Drainage treatment using ES and microalgae hybrid system (KR101605096B), and b: harvesting microalgal biomass (KR101605199B1).

Chemical and physical modifications are used to give ES its magnetic properties, which is cheap, excellent, stable, environmentally friendly and easy to recycle. Heavy metals are adsorbed on the magnetic adsorbent which is then collected by a magnet (Fan, 2016). Another invention uses the same magnetic ES-based adsorbent adapted to remove phosphorus from wastewater, with a removal efficiency of >99\% (Fan et al., 2017).

Molecularly imprinted polymers (MIPs) are adsorbents for removal of environmental pollutants. Production of MIPs via the oil-in-water emulsion strategy requires the addition of surfactants that are harmful to the environment. Replacing surfactant with solid particles produces a Pickering emulsion, an emulsion that is stabilized by solid particles which adsorb onto the interface between the two phases. ES powder consists of solid particles that will stabilize a Pickering emulsion without any surface modification. Moreover, ES powder becomes magnetic with introduction of $\mathrm{Fe}_{3} \mathrm{O}_{4}$ NPs; their magnetic separation with an external magnetic field is straightforward. Magnetic imprinted microspheres produced in this manner exhibited selective recognition ability and adsorption capacity for the antibiotic erythromycin that is present in waste and river water (Zhu et al., 2019).

\section{RECENT RESEARCH ACTIVITIES OF EGGSHELL}

In addition to aforementioned patent-based survey of various ES biotechnological applications, recent research activities continue to be focused on developing high-value products from ES. Recent advances of ES in catalysis and mechanochemistry are summarized in a review paper (Baláž et al., 2021). To improve the poor bioavailability of calcium (Ahmed et al., 2019a), ES can be processed into nano-scale particles that exhibit higher water absorption capability and lower zeta potential, compared to micro-scale ES powder (El-Shibiny et al., 2018). Ball milling of micro-scale ES using zirconia balls in the presence of acetone (wet milling) facilitates the production of ES NPs in the size range of 1-100 nm (Puspitasari et al., 2019).

Eggshell-derived material showed great potential as an electrode for batteries and supercapacitors. ES can be utilized as a cathode, while calcined ES can be used as an anode (Minakshi et al., 2019). ES powder was also evaluated as a corrosion inhibitor for stainless steel (SS, Type 904) in an $\mathrm{H}_{2} \mathrm{SO}_{4}$ environment, and reduced the corrosion rate of SS (904) with 99\% efficiency. In this regard, ES powder has potential as a mixed-type inhibitor with a predominant cathodic effect (Sannia et al., 2019). Furthermore, micronized ES powder has been exploited as an inert supplement, since partial cement replacement using ES powder produced concrete with a higher compressive modulus (Jhatial et al., 2019). In another application, ES powder was assessed as a fire retardant to produce fire-resistant cotton fabrics. Treated fabric incorporating ES shows lower flammability than the untreated material (Tseghai et al., 2019).

There are a number of interesting recent biomedical applications of ES, which has been evaluated as a scaffold component for bone regeneration. ES particle-reinforced gelatin hydrogels displayed superior mechanical properties and enabled the differentiation of pre-osteoblasts with significant enhancement in mineralization (Wu et al., 2019). Similarily, ES and nanotextured ES (NTES, phosphoric acid-mediated) particles incorporated into chitosan-alginate co-polymer scaffolds exhibited improved physicochemical properties along with enhanced mesenchymal stem cells retention, viability, and differentiation (Calvert, 2019). Nanocomposite electrospun fibers fabricated from poly(lactic) acid and needle-like HAP NPs derived from ES showed improved thermal and mechanical properties along with numerous pores and rough edges suitable for osteoblast cell attachment (Apalangya et al., 2019). In addition, scaffolds fabricated via simultaneous electrospinning of poly ( $\varepsilon$-caprolactone)/polyvinyl alcohol/carbon dot in combination with ES-derived calcium phosphate supported a superior osteogenic differentiation and proliferation rate for human buccal fat pad-derived stem cells (Shafiei et al., 2019). Further, the nanocomposites prepared by mixing (2,2,6,6-tetramethylpiperidin-1-yl)oxyl (TEMPO)-oxidized cellulose nanofibrils (TCNFs) with HAP derived from ES led to the formation of composite with superior mechanical properties and uniform distribution of HAP particles. The fabricated composites improved the viability of human bone-derived osteoblasts (Ingole et al., 2020). 


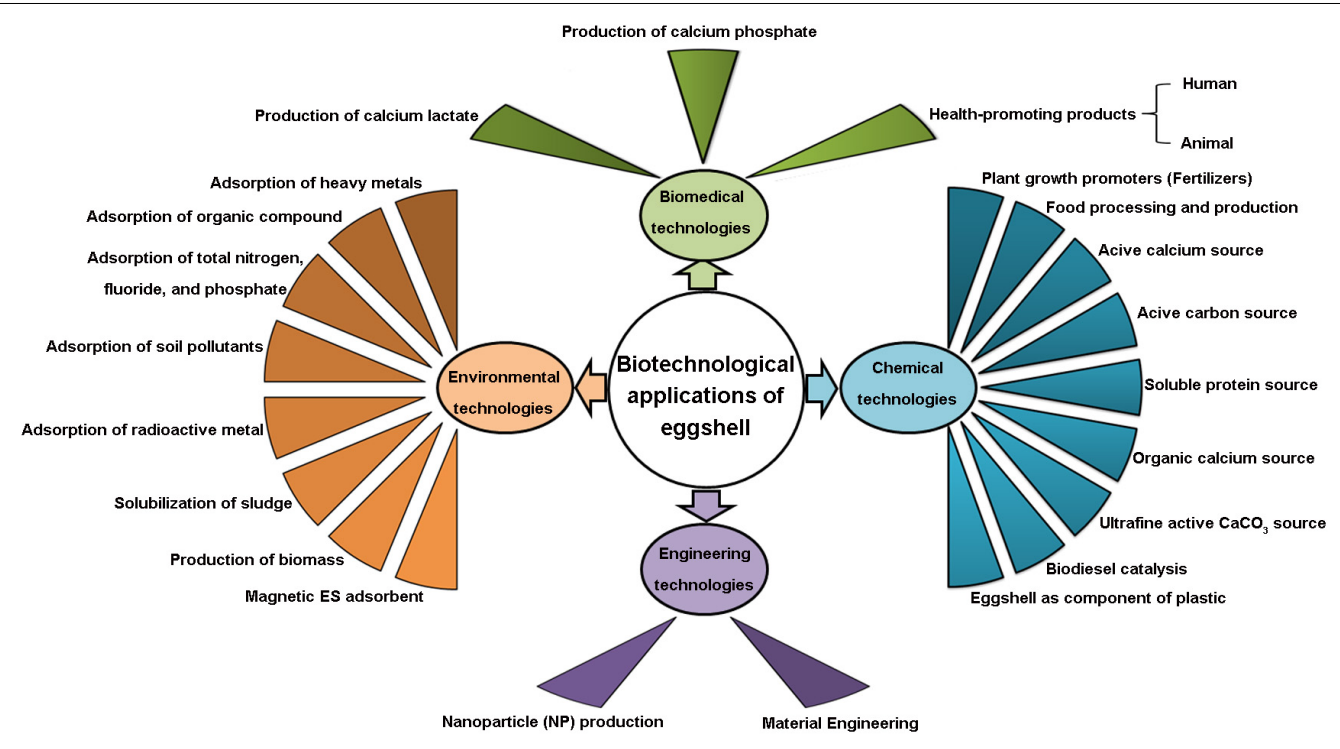

FIGURE 9 | Schematic overview of biotechnological applications of eggshell.

Moreover, a composite fabricated from chitosan combined with ES-derived HAP exhibited enhanced thermal stability and roughness and showed reduced cytotoxicity when tested against human osteosarcoma cells (Saos-2; Trakoolwannachai et al., 2019). Finally, ES-HAP has been evaluated in multiple clinical studies as a substitute material in guided bone regeneration in oral surgery and showed positive outcomes when used for both cyst and socket defect models (Opris et al., 2020).

\section{CONCLUSION AND PROSPECTS}

In developed countries, almost one-third of shell eggs are diverted to egg breaking facilities to produce liquid eggs, leading to the generation of large amount of ES waste. ES disposal in landfill has a deleterious environmental impact. However, ES possesses characteristic biochemical, chemical and physical properties that make it an ideal raw biomaterial for various applications. This review has summarized the biotechnological applications of ES as a valuable bio-resource in terms of devices and methods patented between 2015 and 2020, which is a reasonable snapshot to capture its application scope. Creating value-added uses for ES waste is a sustainable waste management strategy, as it reduces the consumption of natural resources (limestone reserves) and reuses a valuable natural biomaterial while minimizing waste generation. In addition, such a strategy decreases the costs associated with disposal of ES waste. This overview of ES-based invention disclosures confirms the technological and economic feasibility of ES upscaling that attracts diverse industries to exploit its applications. Biotechnological applications of ES include patented inventions in the fields of biomedical, chemical, engineering, and environmental technologies. An overall schematic presentation of ES-based biotechnological applications is shown in Figure 9. The production of $\beta$-TCP and HAP for bone regeneration is a very promising biomedical application. ES as a source of ultrafine active $\mathrm{CaCO}_{3}$ and as an environmentally friendly packaging material are novel ESbased chemical technologies. Top-down strategies to produce ES-derived NPs represent a novel direction for engineering technologies. Innovative environmental applications of ES include the fabrication of magnetic ES adsorbents, adsorption of radioactive metals, and sludge solubilization. Engineering technologies for screening, separation, washing, sterilization, and processing are crucial steps to generate high-quality ES for value-added applications. Although such applications show enhanced economic value, ES byproducts are still relatively undervalued. In spite of the exponential increase in the number of ES - derived patents over the last decade, continued exploration of novel top-down approaches and further development of ES as a physical platform is essential to maximize its value.

\section{AUTHOR CONTRIBUTIONS}

TA, LW, MY, and MH approved of the manuscript's content and warrant that this review manuscript is not under consideration for publication elsewhere. All coauthors have contributed in a significant way to the final format of the review.

\section{FUNDING}

Preparation of this review was supported by funding from the Natural Sciences and Engineering Research Council to MH (NSERC-discovery RGPIN/2016-04410 and NSERC CRD CRDPJ/514335-2017). 


\section{REFERENCES}

Ahmed, T. A. E., Kulshreshtha, G., and Hincke, M. (2019a). "Value-added uses of eggshell and eggshell membranes," in Eggs As functional Foods and Nutraceuticals for Human Health, ed. J. Wu (London: The Royal Society of Chemistry), 359-397. doi: 10.1039/9781788013833

Ahmed, T. A. E., Suso, H. P., Maqbool, A., and Hincke, M. T. (2019b). Processed eggshell membrane powder: bioinspiration for an innovative wound healing product. Mater. Sci. Eng. C Mater. Biol. Appl. 95, 192-203. doi: 10.1016/j.msec. 2018.10.054

Ahmed, T. A. E., Younes, M., Wu, L., and Hincke, M. T. (2021). A survey of recent advances in engineering technology for the screening, separation and processing of eggshell. Front. Bioeng. Biotechnol. 9:677559. doi: 10.3389/fbioe. 2021.677559

Ahuja, K., and Rawat, A. (2019). Calcium Phosphate Market Outlook - Industry Size, Share Report 2025. Glob. Mark. Insights Inc. Pune: Glob. Mark. Insights Inc. Available online at: https://www.gminsights.com/industry-analysis/calciumphosphate-market

Almeida, P. V., Santos, A. F., Lopes, D. V., Gando-Ferreira, L., and Quina, M. J. (2020). Novel adsorbents based on eggshell functionalized with iron oxyhydroxide for phosphorus removal from liquid effluents. J. Water Process Eng. 36:101248. doi: 10.1016/j.jwpe.2020.101248

Apalangya, V. A., Rangari, V. K., Tiimob, B. J., Jeelani, S., and Samuel, T. (2019). Eggshell based nano-engineered hydroxyapatite and poly(lactic) acid electrospun fibers as potential tissue scaffold. Int. J. Biomater. 2019:6762575. doi: 10.1155/2019/6762575

Athanasiadou, D., Jiang, W., Goldbaum, D., Saleem, A., Basu, K., Pacella, M. S., et al. (2018). Nanostructure, osteopontin, and mechanical properties of calcitic avian eggshell. Sci. Adv. 4:eaar3219. doi: 10.1126/sciadv.aar3219

Baláž, M. (2014). Eggshell membrane biomaterial as a platform for applications in materials science. Acta Biomater. 10, 3827-3843. doi: 10.1016/j.actbio.2014. 03.020

Baláž, M., Boldyreva, E. V., Rybin, D., Pavlovic, S., Rodríguez-Padrón, D., Mudrinic, T., et al. (2021). State-of-the-art of eggshell waste in materials science: recent advances in catalysis, pharmaceutical applications, and Mechanochemistry. Front. Bioeng. Biotech. 8:612567. doi: 10.3389/fbioe.2020. 612567

Bone Health Original. Available online at: https://reddremedies.com/products/ bone-health-original?_pos=1\&_psq=bone\&_ss=e\&_v=1.0

Calvert, N. (2019). Composite Hydrogel Scaffolds with Eggshell Particles As A Novel Bone Regeneration Material. Master's thesis. Ottawa, ON: University of Ottawa.

Canadian Food Innovators (2015). Turning Egg Shells Into a Functional Food Ingredient. Can. Food Innov. Available online at: https: //canadianfoodinnovators.ca/project/turning-egg-shells-into-a-functionalfood-ingredient (accessed November 5, 2020).

Cao, Z. (2018). A Kind of to Utilize the Wood-Plastic Material and Preparation Method Thereof for Discarding Eggshell. State Intellectual Property Office of the People's Republic of China, CN108485068A. Inventor; Hefei Oaks New Building Materials Co., Ltd., Assignee. Beijing: State Intellectual Property Office of the People's Republic of China.

Capoani, K. D. (2016). Process of Obtaining Organic Fertilizer From the Mixture of Poultry Manure and Eggshells. Brazilian Patent and Trademark Office, BRPI1104240A2. inventor; Kaue De Queiroz Capoani, Assignee. Rio de Janeiro: Brazilian Patent and Trademark Office.

Chakraborty, A. P., and Gaonkar, M. (2016). Eggshell as calcium supplement tablet. Int. J. Anim. Biotechnol. Appl. 2, 1-6. doi: 10.37628/ijaba.v2i1.55

Chen, C. (2018). A Kind of Modified Egg-Shell Meal and its Preparation Method and Application. State Intellectual Property Office of the People's Republic of China, CN108905987A. inventor; Chunnv Chen, assignee. Beijing: State Intellectual Property Office of the People's Republic of China.

Chen, L., Huang, Q., Huang, X., Tao, L., An, F., Li, S., et al. (2019). A Kind of Preparation Method of Enzymatic Hydrolysis and Fermentation in Combining Conversion Extraction Eggshell Calcium Lactate. State Intellectual Property Office of the People's Republic of China, CN109998116A. inventor; Fujian Agriculture and Forestry University, assignee. Beijing: State Intellectual Property Office of the People's Republic of China.

Chen, X. (2017). It is A Kind of Based on Ion Liquid Modified Egg Shell/Acticarbon and Preparation Method Thereof. State Intellectual Property Office of the People's
Republic of China, CN106955677A. inventor; Foshan Feishida New Material Technology Co., Ltd., assignee. Beijing: State Intellectual Property Office of the People's Republic of China.

Choi, H. (2020). Hybrid Absorbent Using Sericite and Waste Eggshell for Removal of Heavy Metal in Aqueous Solution and Method of the Same. Korea Intellectual Property Rights Information Service, KR20200038657A. inventor; Catholic Kwandong University Industry-Academic Cooperation Foundation, Ltd., assignee. Gangneung: Catholic Kwandong University.

Choi, H. (2016a). Method of Harvesting Microalgal Biomass Using Egg Shells. Korea Intellectual Property Rights Information Service, KR101605199B1. inventor; Catholic Kwandong University Industry-Academic Cooperation Foundation, $L t d$., assignee. Gangneung: Catholic Kwandong University.

Choi, H. (2016b). Methode of Acid Mine Drainage Treatment using Eggshell and Microalgae Hybrid System. Korea Intellectual Property Rights Information Service, KR101605096B1. inventor; Catholic Kwandong University IndustryAcademic Cooperation Foundation, Ltd., assignee. Gangneung: Catholic Kwandong University.

Cordeiro, C. M., and Hincke, M. T. (2011). Recent patents on eggshell: shell and membrane applications. Recent Pat. Food Nutr. Agric. 3, 1-8. doi: 10.2174/ 2212798411103010001

CORDIS CORDIS | European Commission. Brussels: European Commission.

Cree, D., and Rutter, A. (2015). Sustainable bio-inspired limestone eggshell powder for potential industrialized applications. ACS Sustain. Chem. Eng. 3, 941-949. doi: 10.1021 /acssuschemeng.5b00035

Ding, J. (2018). A Kind of Preparation Method of Eggshell Base Porous Solid Alkali. State Intellectual Property Office of the People's Republic of China, CN108726901A. inventor; Jiapeng Ding, assignee. Beijing: State Intellectual Property Office of the People's Republic of China.

Eggshell Calcium Supplement. Available online at: https://irrawsistiblepetfoods. com/products/irrawsistible-eggshell-calcium-supplement?_pos=1\&_sid= 0eb0abc02\&_ss=r

El-Shibiny, S., Abd El-Gawad, M. A. M., Assem, F. M., and El-Sayed, S. M. (2018). The use of nano-sized eggshell powder for calcium fortification of cow's and buffalo's milk yogurts. Acta Sci. Polonorum Technol. Aliment. 17, 37-49. doi: 10.17306/J.AFS.2018.0541

Fan, S. (2016). The Preparation Method of Modified Eggshell Magnetic Adsorbent and the Method for Removing Heavy Metal in Water Removal. State Intellectual Property Office of the People's Republic of China, CN105771876B. inventor; Baoji University of Arts and Sciences, assignee. Beijing: State Intellectual Property Office of the People's Republic of China.

Fan, S., Lei, J., Zhou, Q., Zhang, Z., Li, M., Luo, J., et al. (2017). The Preparation of the Useless Modified Dephosphorization Magnetic Adsorptive Material of Eggshell and the Minimizing Technology of Phosphorus in Water. State Intellectual Property Office of the People's Republic of China, CN106925233A. inventor; Baoji University of Arts and Sciences, assignee. Beijing: State Intellectual Property Office of the People's Republic of China.

FAO (2020). Livestock Primary. FAOSTAT. Rome: FAO.

Gaber, M. A. W. (2018). Characterizations of El Minia limestone for manufacturing paper filler and coating. Egypt. J. Pet. 27, 437-443. doi: 10.1016/j.ejpe.2017. 07.007

Gao, H., Cai, M., Liao, Y., Liu, X., Yan, Y., and Du, J. (2017). A Kind of Preparation Method and Application of the Adsorbent for Heavy Metal Based on Modified Egg Shell. State Intellectual Property Office of the People's Republic of China, CN107051401A. inventor; China West Normal University, assignee. Beijing: State Intellectual Property Office of the People's Republic of China.

Giango, W. C., Manalastas, R. D., Villaganas, A. A., Himang, C. M., and Giango, M. K. C. (2017). Formulation of Eggshell Cupcake. The Intellectual Property Office of the Philippines, PH22017000682U1. inventor; Cebu Technological Univ - Main Campus, assignee. Taguig: The Intellectual Property Office of the Philippines.

Guedes, F. H., França, J. N., and Faria Júnior, R. D. (2016). Calcium Sililcate Produced with Ceramic Mass Consisting of Eggshell Residue and Red Ceramic Chamote. Brazilian Patent and Trademark Office, BR102014019912A2. inventor; State University Of Northern Fluminense Darcy Ribeiro, assignee. Rio de Janeiro: State University Of Northern Fluminense Darcy Ribeiro.

He, W., Yang, S., Xue, J., Zhao, J., Zhao, L., and You, X. (2018). A Kind of Eggshell Adsorbent and the Preparation Method and Application Thereof. State 
Intellectual Property Office of the People's Republic of China, CN108311093A. inventor; Institute of Agricultural Quality Standards and Testing Technology, Chinese Academy of Agricultural Sciences, assignee. Beijing: State Intellectual Property Office of the People's Republic of China.

Hincke, M. T., Nys, Y., Gautron, J., Mann, K., Rodriguez-Navarro, A. B., and McKee, M. D. (2012). The eggshell: structure, composition and mineralization. Front. Biosci. (Landmark Ed) 17, 1266-1280. doi: 10.2741/3985

Huang, D., Zhang, S., Zhang, B., Huang, D., Ren, Q., Zhou, Z., et al. (2017). A Kind of Lime-Preserved Egg Shell Adsorbent of Uranium and its Preparation Method and Application. State Intellectual Property Office of the People's Republic of China, CN106925205A. inventor; East China Institute of Technology, assignee. Beijing: State Intellectual Property Office of the People's Republic of China.

Huang, Q., Huang, X., Yang, R., An, F., Huang, Q., Li, S., et al. (2019). A Kind of Method that Compound Lactobacillus-Fermencucumber Eggshell Prepares Calcium Lactate. State Intellectual Property Office of the People's Republic of China, CN110373444A. inventor; Fujian Agriculture and Forestry University, assignee. Beijing: State Intellectual Property Office of the People's Republic of China.

Hyun, K. (2015). Method for Manufacturing Eggshells Calcium Solubility in Water Using Eggshells. Korea Intellectual Property Rights Information Service, KR20150028061A. inventor; Kyungtae Hyun, assignee. Daejeon: Korea Intellectual Property Rights Information Service.

Imbabi, M. S., Carrigan, C., and McKenna, S. (2012). Trends and developments in green cement and concrete technology. Int. J. Sustain. Built Environ. 1, 194-216. doi: 10.1016/j.ijsbe.2013.05.001

Ingole, V. H., Vuherer, T., Maver, U., Vinchurkar, A., Ghule, A. V., and Kokol, V. (2020). Mechanical properties and cytotoxicity of differently structured nanocellulose-hydroxyapatite based composites for bone regeneration application. Nanomaterials 10:25. doi: 10.3390/nano10010025

Jhatial, A. A., Sohu, S., Memon, M. J., Bhatti, N., and Memon, D. (2019). Eggshell powder as partial cement replacement and its effect on the workability and compressive strength of concrete. IJAAS 6, 71-75. doi: 10.21833/ijaas.2019. 09.011

Jin, X. (2018). A Kind of Distribution of the Feed of Lobster Containing Eggshell. State Intellectual Property Office of the People's Republic of China, CN108185230A. inventor; Suzhou Chengen Aquatic Products Technology Co., Ltd., assignee. Beijing: State Intellectual Property Office of the People's Republic of China.

Just Egg Ltd (2020). Sustainability. JustEgg Chill. Foods Ltd. Available online at: http://justegg.co.uk/about-us/sustainability/ (accessed November 5, 2020).

Kang, G. (2016). Soap Composition Comprising Eggshells. Korea Intellectual Property Rights Information Service, KR101627300B1. inventor; Geun-young Kang, assignee.

Katsuyama, Y., Yamasaki, A., Iizuka, A., Fujii, M., Kumagai, K., and Yanagisawaa, Y. (2005). Development of a process for producing high-purity calcium carbonate $(\mathrm{CaCO} 3)$ from waste cement using pressurized $\mathrm{CO} 2$. Environ. Prog. 24, 162-170. doi: 10.1002/ep.10080

Kim, K., Park, H., and Park, D. (2018). Manufacturing Method of Natural Organic Liquid Fertilizer using Discarded Eggshell and Natural Organic Liquid Fertilizer Prepared Thereby. Korea Intellectual Property Rights Information Service, KR101872722B1. inventor; Sharing Co., Ltd., assignee.

Laca, A., Laca, A., and Diaz, M. (2017). Eggshell waste as catalyst: a review. J. Environ. Manage 197, 351-359. doi: 10.1016/j.jenvman.2017.03.088

Lagumen, R. M., and Colmo, J. V. (2016). A Process of Producing Building Blocks with Eggshells as Cement Extender. The Intellectual Property Office of the Philippines, PH22016000254U1. inventor; Sultan Kudarat State University, assignee.

Lee, G. (2018). Human Friendly Calcium Phosphate for Artificial Bone Using Eggshell. Korea Intellectual Property Rights Information Service, KR101909747B1. inventor; Hannam Ceramic Co., Ltd., assignee.

Lee, M., Yun, Y., and Kim, D. (2019). Enhanced economic feasibility of excess sludge treatment: acid fermentation with biogas production. BMC Energy 1:2. doi: 10.1186/s42500-019-0001-x

Lee, S., and Kang, T. (2019). Calcium Phosphate Bioglass Using Egg Shell And Manufacturing Method Thereof. Korea Intellectual Property Rights Information Service, KR101998154B1. inventor; Mokpo National University IndustryAcademic Cooperation Foundation, Ltd., assignee.

Lee, S., and Kang, T. (2018). Manufacturing Method Of Calcium Phosphate Using Eggshell and Phosphate-ammonia Solution. Korea Intellectual Property Rights
Information Service, KR101907408B1. inventor; Mokpo National University Industry-Academic Cooperation Foundation, Ltd., assignee.

Lee, S., and Kang, T. (2017). Synthesis of Calcium Phosphate Derived from Calcined Eggshell and Phosphoric Acid Solution. Korea Intellectual Property Rights Information Service, KR20170109371A. inventor; Mokpo National University Industry-Academic Cooperation Foundation, Ltd., assignee.

Lee, S., Milcha, C. P., and Kang, T. (2016). Synthesis of Hydroxyapatite Using Room-Temperature Reaction Between Eggshell and Phosphoric Acid. Korea Intellectual Property Rights Information Service, KR20160112407A. inventor; Mokpo National University Industry-Academic Cooperation Foundation, Ltd., assignee.

Lewicka, E., Szlugaj, J., Burkowicz, A., and Galos, K. (2020). Sources and markets of limestone flour in Poland. Resources 9:118. doi: 10.3390/resources91 00118

Li, H., and Yan, F. (2020). Method for Removing Total Nitrogen in Water by Using Modified Eggshells. State Intellectual Property Office of the People's Republic of China, CN110877921A. inventor; Qilu Institute of Technology, assignee.

Li, J. (2018). Eggshell Resin Powder Composition. State Intellectual Property Office of the People's Republic of China, CN108602977A. inventor; Akwan Corporation, assignee.

Li, L. (2020). Egg Shell Powder Polylactic Acid Green Egg Packaging Box. State Intellectual Property Office of the People's Republic of China, CN210392198U. inventor; Hanshan Normal University, assignee.

Li, L. (2019). Egg Shell Powder Polylactic Acid Instant Noodle Packing Box. State Intellectual Property Office of the People's Republic of China, CN209758059U. inventor; Hanshan Normal University, assignee.

Li, L., Tang, G., and Song, G. (2015). Polycaprolactone/Poly Butylene Succinate/EggShell Meal Matrix Material and Method for Making Thereof. State Intellectual Property Office of the People's Republic of China, CN103183938B. inventor; Tsinghua University Shenzhen Graduate School, assignee.

Li, X. (2017). A Kind of Egg Feedstuff Containing Kochia Scoparia Egg-Shell Meal. State Intellectual Property Office of the People's Republic of China, CN106912676A. inventor; Xiaojing Li, assignee.

Limestone (2019). Limestone Market - Growth, Trends, and Forecast (2020 - 2025). Available online at: https://www.cepi.org/key- statistics-2019/ (accessed July 24, 2020).

Liu, C. (2017). The Extracting Method Of Organic Substrate In A Kind Of Birds Eggshell. State Intellectual Property Office of the People's Republic of China, CN105396861B. inventor; Zhejiang Agriculture and Forestry University, assignee.

Liu, F., Wu, Z., and Liu, J. (2015). Eggshell High-Calcium Type Organic Fertilizer And Preparing Method Thereof. State Intellectual Property Office of the People's Republic of China, CN105036828A. inventor; Guangdong Hengfeng Fertilizer Industry Co., Ltd., assignee.

Liu, L., Xiao, F., Chen, K., Meng, Y., Zhao, S., Kang, H., et al. (2018). A Kind Of To Ferment Mutton Sausage And Preparation Method Using Industrial Egg Shell As The High Calcium Of Calcium Source. State Intellectual Property Office of the People's Republic of China, CN108497334A. inventor; Henan University of Science and Technology, assignee.

Lu, G., Luo, W., Ji, Y., Li, H., Dang, Z., and Yi, X. (2018). A Kind Of Heavy Metal Pollution Agricultural Land Soil Opsonizing Method Utilized Based On Eggshell Resource. State Intellectual Property Office of the People's Republic of China, CN108160699A. inventor; South China University of Technology, assignee.

Lu, G., Qu, L., Lin, Z., Dang, Z., Yang, C., Xie, Y., et al. (2017). A Kind Of Method Using The Acid Agricultural Land Soil Of Eggshell Heavy Metal Pollution To Carry Out Improveing. State Intellectual Property Office of the People's Republic of China, CN106269841A. inventor; South China University of Technology, assignee.

Lu, G., Zhang, T., Lin, Z., Tu, Z., Dang, Z., Guo, C., et al. (2016). A Kind Of Method Utilizing Eggshell Fixed Bed Same For Treating Acidic Mine Wastewater. State Intellectual Property Office of the People's Republic of China, CN106186166A. inventor; South China University of Technology, assignee.

Ma, M., Deng, S., Jin, Y., and Geng, F. (2015). One Plant Height Lactic AcidProducing Bacteria And Fermentation Eggshell Thereof Prepare The Method For Calcium Lactate. State Intellectual Property Office of the People's Republic of China, CN103898016B . inventor; Huazhong Agricultural University, assignee.

Ma, M., Li, C., Cai, Z., and Geng, F. (2016). The Preparation Method Of A Kind Of Eggshell Ultramicro Active Calcium Carbonate. State Intellectual Property 
Office of the People's Republic of China, CN104229851B. inventor; Huazhong Agricultural University, assignee.

Ma, M., Zhang, M., Sheng, L., and Fu, X. (2017). Method of Co-Purifing Three Microfunctional Proteins From Eggshell. State Intellectual Property Office of the People's Republic of China, CN106632646A. inventor; Huazhong Agricultural University, assignee.

Ma, M., and Zhao, J. (2019). A Kind Of Method That Immobilization Fermentation Egg-Shell Meal Prepares Calcium Lactate. State Intellectual Property Office of the People's Republic of China, CN110079562A. inventor; Huazhong Agricultural University, assignee.

Mignardi, S., Archilletti, L., Medeghini, L., and De Vito, C. (2020). Valorization of eggshell biowaste for sustainable environmental remediation. Sci. Rep. 10:2436. doi: 10.1038/s41598-020-59324-5

Minakshi, M., Higley, S., Baur, C., Mitchell, D. R. G., Jones, R. T., and Fichtner, M. (2019). Calcined chicken eggshell electrode for battery and supercapacitor applications. RSC Adv. 9, 26981-26995. doi: 10.1039/c9ra04289j

Mordor Intelligence (2020). Available online at: https://www.mordorintelligence. com/industry-reports/limestone-market (accessed December 4, 2020).

Neunzehn, J., Szuwart, T., and Wiesmann, H. P. (2015). Eggshells as natural calcium carbonate source in combination with hyaluronan as beneficial additives for bone graft materials, an in vitro study. Head Face Med. 11:12. doi: 10.1186/s13005-015-0070-0

Nuhu, A. A., Basheer, C., Shaikh, A. A., and Al-Arfaj, A. R. (2015). Determination of Polycyclic Aromatic Hydrocarbons In Water Using Nanoporous Material Prepared From Waste Avian Egg Shell. United States Patent and Trademark Office, US20150377752A1. inventor; King Fahd University of Petroleum and Minerals, assignee. doi: 10.1155/2012/305691

Nys, Y., Gautron, J., Garcia-Ruiz, J. M., and Hincke, M. T. (2004). Avian eggshell mineralization: biochemical and functional characterization of matrix proteins. C. R. Palevol. 3, 549-562. doi: 10.1016/j.crpv.2004.08.002

Opris, H., Bran, S., Dinu, C., Baciut, M., Prodan, D. A., Mester, A., et al. (2020). Clinical applications of avian eggshell-derived hydroxyapatite. Bosnian J. Basic Med. Sci. 2, 430-437. doi: 10.17305/bjbms.2020.4888

EuLA (2020). Other Industrial Consumers \& Manufacturing - EuLA: European Lime Association. Brussels: European Lime Association.

OVOCET. Available online at: https://www.eggnovo.com/products/

Owuamanam, S., and Cree, D. (2020). Progress of bio-calcium carbonate waste eggshell and seashell fillers in polymer composites: a review. J. Compos. Sci. 4:72. doi: $10.3390 / j \operatorname{cs} 4020070$

Pan, Y., and Tang, P. (2020). Method for Preparing Defluorination Water Purifying Agent By Using Eggshells And Application Thereof. State Intellectual Property Office of the People's Republic of China, CN111085158A. inventor; Jinan University, assignee.

Panait, A. M., Moncea, M. A., Dumitru, F. D., and Deak, G. (2020). Process For Preparing Calcium Hydroxide Nanopowder Using Eggshell Wastes From Industrial Activities - Provco-Nap. State office for innovation and brands Bucharest, Romania, RO133975A0. inventor; National Research and Development Institute for Environmental Protection, assignee.

Park, H. J., Jeong, S. W., Yang, J. K., Kim, B. G., and Lee, S. M. (2007). Removal of heavy metals using waste eggshell. J. Environ. Sci. (China) 19, 1436-1441. doi: 10.1016/S1001-0742(07)60234-4

Poultry Innovations Conference (2013). PIC Update: Potential For Eggshell Waste. Can. Poult. Mag. Available online at: https://www.canadianpoultrymag. com/pic-update-potential-for-eggshell-waste-10007/ (accessed November 6, 2020).

POWDER TRAP. Available online at: https://powdertrap.com/product/clusterbuster/

Puspitasari, P., Yuwanda, V., Sukarni, and Dika, J. W. (2019). The properties of eggshell powders with the variation of sintering duration. IOP Conf. Series Mat. Sci. Eng. 515:12104. doi: 10.1088/1757-899x/515/1/012104

Qiu, J., Lin, Q., Wang, L., Zhang, S., Zhang, D., Li, L., et al. (2017). A Kind Of Eggshell Load Zinc Oxide Material And Its Preparation Method And Application. State Intellectual Property Office of the People's Republic of China, CN106902760A. inventor; Jinling Institute of Technology, assignee.

Quina, M. J., Soares, M. A. R., and Quinta-Ferreira, R. (2017). Applications of industrial eggshell as a valuable anthropogenic resource. Resour. Conserv. Recycl. 123, 176-186. doi: 10.1016/j.resconrec.2016.09.027
Ran, X., Li, J., Xu, Y., Sun, Q., and Zeng, L. (2018). Polypeptide Chelate Calcium Preparation And Preparation Method Thereof. State Intellectual Property Office of the People's Republic of China, CN104920782A. inventor; Sichuan University, assignee.

Rangari, V., and Tiimob, B. (2019). Nano Engineered Eggshell Flexible Biopolymer Blend And Methods Of Making Biopolymer Blend Film And Using Such Bioplastic Blends For Improved Biodegradeable Applications. United States Patent and Trademark Office US20190023896A1. inventor; Tuskegee University, assignee.

ReportLinker (2020). Calcium Carbonate Market Research Report by Type, by Industry - Global Forecast to 2025 - Cumulative Impact of COVID-19. Available online at: https://www.reportlinker.com/p05913702/CalciumCarbonate-Market-Research-Report-by-Type-by-Industry-Global-Forecastto-Cumulative-Impact-of-COVID-19.html?utm_source $=\mathrm{GNW}$

Rose, M. L., and Hincke, M. T. (2009). Protein constituents of the eggshell: eggshellspecific matrix proteins. Cell Mol. Life Sci. 66, 2707-2719. doi: 10.1007/s00018009-0046-y

Sannia, O., Popoola, A. P. I., and Fayomi, O. S. I. (2019). Electrochemical analysis of austenitic stainless steel (Type 904) corrosion using egg shell powder in sulphuric acid solution. Energy Proc. 157, 619-625. doi: 10.1016/j.egypro.2018. 11.227

Santos, A. F., Arim, A. L., Lopes, D. V., Gando-Ferreira, L. M., and Quina, M. J. (2019). Recovery of phosphate from aqueous solutions using calcinated eggshell as an eco-friendly adsorbent. J. Environ. Manage. 238, 451-459. doi: 10.1016/j. jenvman.2019.03.015

Schaafsma, A., Pakan, I., Hofstede, G. J., Muskiet, F. A., Van Der Veer, E., and De Vries, P. J. (2000). Mineral, amino acid, and hormonal composition of chicken eggshell powder and the evaluation of its use in human nutrition. Poult. Sci. 79, 1833-1838. doi: $10.1093 / \mathrm{ps} / 79.12 .1833$

Shagdar, J., and Myagmar, O. (2017). Natural Compositions Containing Eggshell Calcium, Organic Honey And Lemon. United States Patent and Trademark Office, US2017266225A1. inventor; Jargalsaikhan Shagdar and Odonchimeg Myagmar, assignee. Washington, DC: United States Patent and Trademark Office.

Shafiei, S., Omidi, M., Nasehi, F., Golzar, H., Mohammadrezaei, D., Rad, M. R., et al. (2019). Egg shell-derived calcium phosphate/carbon dot nanofibrous scaffolds for bone tissue engineering: fabrication and characterization. Mater. Sci. Eng. C Mater. Biol. Appl. 100, 564-575. doi: 10.1016/j.msec.2019.03.003

Shahbandeh, M. (2020). Global Egg Production From 1990 To 2018 (In 1,000 Metric Tons). (2020). Available online at: https://www.statista.com/statistics/263972/ egg-production-worldwide-since-1990/ (accessed August 20, 2020).

Shao, Y. (2017). Method for Preparing Organic Calcium With Eggshells. State Intellectual Property Office of the People's Republic of China, CN106307551A. inventor; Yuhua Shao, assignee. Beijing: State Intellectual Property Office of the People's Republic of China.

Shearman, S. (2016). Scotch Egg Company Claims To Have Cracked Problem Of Eggshell Waste. The Guardian. Available online at: http://www.theguardian.com/sustainable-business/2016/jun/30/scotchegg-company-cracked-eggshell-waste-problem-recycling-plastic (accessed November 5, 2020).

Shellbrane (2012). SHELLBRANE (Separating Eggshell And Its Membrane To Turn Eggshell Waste Into Valuable Source Materials). CORDIS. Available online at: https://cordis.europa.eu/project/id/286910/reporting (accessed November 5, 2020).

Shellbrane (2019). Separating Eggshell And Its Membrane To Turn Eggshell Waste Into Valuable Source Materials. Available online at: https://web.archive.org/ web/20190721001656/http://shellbrane.eu/ (accessed November 6, 2020).

Shi, Y., Zhang, Z., Li, T., Wang, L., Zhao, B., Li, J., et al. (2019). A Kind Of Method For Preparation Of Active Carbon Based On Eggshell And Saccharide Compound. State Intellectual Property Office of the People's Republic of China, CN110217791A. inventor; Tianjin Polytechnic University, assignee. Tianjin: Tianjin Polytechnic University.

Stapane, L., Le Roy, N., Hincke, M. T., and Gautron, J. (2019). The glycoproteins EDIL3 and MFGE8 regulate vesicle-mediated eggshell calcification in a new model for avian biomineralization. J. Biol. Chem. 294, 14526-14545. doi: 10. 1074/jbc.RA119.009799

Sun, Z. (2017a). A Kind Of Preparation Method Of The Compound Lithium Battery Absorbent Of Egg Shell Waste Material/Activated Carbon. State Intellectual 
Property Office of the People's Republic of China, CN106902787A. inventor; Zhiting Sun, assignee. Beijing: State Intellectual Property Office of the People's Republic of China.

Sun, Z. (2017b). A Kind Of Waste Modified Activated Carbon Of Egg Shell Is Combined The Preparation Method Of Arsenic Removal Filter Core. State Intellectual Property Office of the People's Republic of China, CN106943801A. inventor; Zhiting Sun, assignee. Beijing: State Intellectual Property Office of the People's Republic of China.

Tian, R. (2014). Eggshell Heavy Metal Ion Adsorbent And Preparation Method Thereof. State Intellectual Property Office of the People's Republic of China, CN102658090B. inventor; Dalian Jiaotong University, assignee. Dalian: Dalian Jiaotong University.

Tian, R. (2015). Method for Preparing Porous Material By Use Of Eggshell And Waste Glass. State Intellectual Property Office of the People's Republic of China, CN104609734A. inventor; Dalian Jiaotong University, assignee. Dalian: Dalian Jiaotong University.

Trakoolwannachai, V., Kheolamai, P., and Ummartyotin, S. (2019). Development of hydroxyapatite from eggshell waste and a chitosan-based composite: in vitro behavior of human osteoblast-like cell (Saos-2) cultures. Int. J. Biol. Macromol. 134, 557-564. doi: 10.1016/j.ijbiomac.2019.05.004

Tseghai, G. B., Berhe, B. T., and Wakjira, Y. T. (2019). Producing fire retardant cotton fabric using chicken eggshell. J. Textile Sci. Eng. 9:1000396. doi: 10.4172/ 2165-8064.1000396

Urlovskis, G., Pahomova-Strautiņa, J., and Jakovickis, M. (2016). Method For Production Of Hen Eggshell Powder And Preparation Of Food Additives From Acquired Powder. Patent Office of the Republic of Latvia, LV15101A. inventor; Ave Astra, Sia, assignee. Riga: Patent Office of the Republic of Latvia.

USGS (2020). USGS Online Publications Directory| Lime. Reston, VA: USGS. Available online at: https://pubs.usgs.gov/periodicals/mcs2020/

Waheed, M., Butt, M. S., Shehzad, A., Adzahan, N. M., Shabbir, M. A., Suleria, H. A. R., et al. (2019). Eggshell calcium: a cheap alternative to expensive supplements. Trends Food Sci. Technol. 91, 219-230. doi: 10.1016/j.tifs.2019. 07.021

Wang, B., Zhang, X., and Gao, X. (2019). A Kind Of Purposes Of Fowl EggShell Meal. State Intellectual Property Office of the People's Republic of China, CN109437642A. inventor; Yantai University, assignee. Yantai: Yantai University.

Wang, D., Zhou, H., Qi, Z., Liu, X., Liu, G., Li, Y., et al. (2017). Preparation Method Of Eggshell Powder Based Synthetic Paper. State Intellectual Property Office of the People's Republic of China, CN106633808A. inventor; Hunan University of Science and Technology, assignee. Xiangtan: Hunan University of Science and Technology.

Wang, J. (2015a). Eggshell Containing Compound Active Calcium Carbonate. State Intellectual Property Office of the People's Republic of China, CN104910412A. inventor; Anhui Jinhui Environmental Protection Material Co., Ltd., assignee. Beijing: State Intellectual Property Office of the People's Republic of China.

Wang, J., Wu, K., Duan, L., Duan, L., Duan, S., and Duan, Y. (2016). A Kind Of Peel Eggshell Rice Wine Beverage. State Intellectual Property Office of the People's Republic of China, CN106119015A. inventor; Anhui Wejiatian Ecological Agriculture Co., Ltd., assignee. Beijing: State Intellectual Property Office of the People's Republic of China.

Wang, L., Fei, W., Yuan, Y., and Liu, Z. (2019). A Kind Of Graphene And Its Preparation Method And Application Prepared Using Shell Or Eggshell Waste. State Intellectual Property Office of the People's Republic of China, CN109455699A. inventor; Harbin Institute of Technology, assignee. Harbin: Harbin Institute of Technology.

Wang, P., Xie, L., Zhou, Y., and Li, X. (2019). A Method Of High Activity Porous $\mathrm{Ca}(\mathrm{Oh}) 2$ Is Prepared With Eggshell. State Intellectual Property Office of the People's Republic of China, CN109608060A. inventor; Qingdao Rongchuangxin Material Engineering Research Institute Co., Ltd., assignee. Qingdao: Qingdao Rongchuangxin Material Engineering Research Institute Co., Ltd.

Wang, G., and Song, R. (2015). Biodegradable Plastic Taking Egg Shells As Raw Materials And Preparation Method Of Biodegradable Plastic. State Intellectual Property Office of the People's Republic of China, CN104761792A. inventor; Hefei Huanzhao Polymer Material Factory, assignee. Beijing: State Intellectual Property Office of the People's Republic of China.

Wang, S., Yang, Y., Chen, Y., Zhang, Y., Zhu, L., Zhu, Z., et al. (2017). A Kind Of Method That Utilization Eggshell Prepares Egg-Shell Meal Fruits And Vegetables Cleaning Agent. State Intellectual Property Office of the People's Republic of
China, CN107057890A. inventor; Hubei Shendi Agricultural Biotechnology Co., Ltd., assignee. Jingmen: Hubei Shendi Agricultural Biotechnology Co., Ltd.

Wang, Y. (2015b). Method for Preparing Calcium Propionate From Eggshell. State Intellectual Property Office of the People's Republic of China, CN104262132A. inventor; Shaanxi Synmot Petroleum Co., Ltd., assignee. Shaanxi: Shaanxi Synmot Petroleum Co., Ltd.

Wu, X., Stroll, S. I., Lantigua, D., Suvarnapathaki, S., and Camci-Unal, G. (2019). Eggshell particle-reinforced hydrogels for bone tissue engineering: an orthogonal approach. Biomater. Sci. 7, 2675-2685. doi: 10.1039/c9bm0 0230h

Xiang, Y., Wang, L., Li, Y., Jiao, Y., Chen, X., and Wang, R. (2018). ModifiedEggshell Biodiesel Oil Catalyst, And Preparation Method And Application Of Modified-Eggshell Biodiesel Oil Catalyst. State Intellectual Property Office of the People's Republic of China, CN105344344A. inventor; Lipeng Wang, assignee. Beijing: State Intellectual Property Office of the People's Republic of China.

Xiang, Y., Wang, L., Li, Y., Jiao, Y., Xiong, J., and Wang, R. (2019). The Method That Ultrasonic Combined Modified Eggshell Cracks Excess Sludge. State Intellectual Property Office of the People's Republic of China, CN105174681B. inventor; Yulin College, assignee. Beijing: State Intellectual Property Office of the People's Republic of China.

Xie, W. (2018). A Kind Of Chafing Dish Bottom Flavorings Preparation Method Containing Egg Shell Powder. State Intellectual Property Office of the People's Republic of China, CN108013360A. inventor; Wenbo Xie, assignee. Beijing: State Intellectual Property Office of the People's Republic of China.

Xie, Y., Zhu, X., Ren, L., Zhang, L., Wu, Y., Yang, J., et al. (2016). One is Used For Removing Phosphatic Eggshell Loaded Nano-Iron Material And Preparation Method Thereof In Water. State Intellectual Property Office of the People's Republic of China, CN106111048A. inventor; Chengdu University of Technology, assignee. Chengdu: Chengdu University of Technology.

$\mathrm{Xu}, \mathrm{Y}$., Ye, J., Zhou, D., and Su, L. (2020). Research progress on applications of calcium derived from marine organisms. Sci. Rep. 10:18425. doi: 10.1038/ s41598-020-75575-8

Yang, D., Liu, M., and Zhang, X. (2020). Preparation Method And Application Of Eggshell-Loaded Vulcanized Nano Zero-Valent Iron Composite Nano Material. State Intellectual Property Office of the People's Republic of China, CN110665453A. inventor; Quanzhou Normal University, assignee.

Yang, D., Shi, W., and Liu, M. (2019a). A Kind Of Preparation Method And Application Of The Copper Selenide Nanometer Material Based On Egg Shell Template. State Intellectual Property Office of the People's Republic of China, CN109772372A. inventor; Quanzhou Normal University, assignee.

Yang, D., Shi, W., and Zhang, X. (2019b). A Kind Of Copper Nano Material Based On Egg Shell Template And Preparation Method Thereof, Antibacterial Applications. State Intellectual Property Office of the People's Republic of China, CN110000397A. inventor; Quanzhou Normal University, Quanzhou Xufeng Powder Material Co., Ltd., assignee.

Yang, D., Zhang, B., and Liu, M. (2017). A Kind Of To Prepare CaCO3 by Template Of Egg-Shell Meal The Method Of Ag Composites. State Intellectual Property Office of the People's Republic of China, CN106862585A. inventor; Quanzhou Normal University, assignee.

Yang, D., Zhang, X., and Shi, W. (2019c). A Kind Of Preparation Method And Application Of The Copper Sulfide Nano Material Based On Egg Shell Template. State Intellectual Property Office of the People's Republic of China, CN109809466A. inventor; Quanzhou Normal University, assignee.

Yang, H., and Shen, J. (2017). A Kind Of Eggshell Byproduct Comprehensive Utilization Method. State Intellectual Property Office of the People's Republic of China, CN106734057A. inventor; Taonan Yuexing Food Technology Co., Ltd., assignee.

Yang, T. (2015). Eggshell Powder Processing Method And Processing Device. State Intellectual Property Office of the People's Republic of China, CN105011172A. inventor; Jilin Houde Food Co., Ltd., assignee.

Yang, Y., Yang, J., and Kim, G. (2019d). Nutritional Supplements For Apple Cultivation Comprising Shell Extract, Egg Shell Powder And Microbial Agent And Manufacturing Method Thereof. Korea Intellectual Property Rights Information Service, KR102006969B1. inventor; Taebong Bio Farming Association Corporation, assignee.

Ye, Y., Ye, C., and Wang, S. (2019). A Method Of Material Is Applied In The Shell Of Prevention And Treatment Skin Ulcer And The Preparation Method Of Eggshell 
Complex Liquid And Its Processing Skin Ulcer Face. State Intellectual Property Office of the People's Republic of China, CN110151855A. inventor; Yangzhou Russell Biotechnology Co., Ltd., assignee.

Yue, X., Cheng, C., Zhou, A., Zhao, B., and Wang, S. (2018). A Kind Of Method That Magnetic Slow Release Carbon Source Is Prepared Using Municipal Sludge And Eggshell As Raw Material. State Intellectual Property Office of the People's Republic of China, CN107746166A. inventor; Taiyuan University of Technology, assignee.

Zeng, P. (2019). A Kind Of Egg-Shell Meal Noodle Processing Method. State Intellectual Property Office of the People's Republic of China, CN109452556A. inventor; Chongqing Dingyang Fanshu Agricultural Development Co., Ltd., assignee.

Zhang, S. (2018). Cleanser Composition Containing Eggshell Powder. Intellectual Property Office Taiwan, TWM569227U. inventor; Shuzhen Zhang, assignee. Taipei: Intellectual Property Office Taiwan.

Zhao, B., and Wang, S. (2019). A Method Of Liquid Calcium Acetate Fertilizer Is Prepared Using Eggshell. State Intellectual Property Office of the People's Republic of China, CN109912319A. inventor; Binzhou Xingyang Biological Technology Co., Ltd., assignee.

Zhou, Z., Wu, X., and Qin, Y. (2019). Eggshell Dust-Free Chalk Production Method. State Intellectual Property Office of the People's Republic of China, CN109651895A. inventor; Zhonggang Zhou, assignee. Beijing: State Intellectual Property Office of the People's Republic of China.
Zhu, L., Zhang, Y., Zuo, S., and Li, Y. (2016). A Kind Of Eggshell Source Compound Lemon Acid Biocal And Preparation Method Thereof. State Intellectual Property Office of the People's Republic of China, CN103961688B. inventor; Hubei Shendi Agricultural Technology \& Trade Co., Ltd., assignee. Jingmen: Hubei Shendi Agricultural Technology \& Trade Co., Ltd.

Zhu, Y., Qi, A., Sun, D., Dai, J., Yan, Y., and Li, C. (2019). A Kind Of Method That The Pickering Emulsion Polymerization Technology That Magnetism Egg-Shell Meal Is Stable Prepares Trace Microballoon. State Intellectual Property Office of the People's Republic of China, CN106362654B. inventor; Jiangsu University, assignee.

Conflict of Interest: The authors declare that the research was conducted in the absence of any commercial or financial relationships that could be construed as a potential conflict of interest.

Copyright $\odot 2021$ Ahmed, Wu, Younes and Hincke. This is an open-access article distributed under the terms of the Creative Commons Attribution License (CC BY). The use, distribution or reproduction in other forums is permitted, provided the original author(s) and the copyright owner(s) are credited and that the original publication in this journal is cited, in accordance with accepted academic practice. No use, distribution or reproduction is permitted which does not comply with these terms. 